\title{
R\&D Delegation in a Duopoly with Spillovers
}

\author{
by Désiré VENCATACHELLUM and \\ Bruno VERSAEVEL
}

Cahier de recherche $n^{0}$ IEA-05-01

January 2005

ISSN : 0825-8643

Copyright $(0) 2005$ HEC Montréal.

Tous droits réservés pour tous pays. Toute traduction ou toute reproduction sous quelque forme que ce soit est interdite. Les textes publiés dans la série des Cahiers de recherche HEC n'engagent que la responsabilité de leurs auteurs.

La publication de ce Cahier de recherche a été rendue possible grâce à des subventions d'aide à la publication et à la diffusion de la recherche provenant des fonds de l'École des HEC.

Direction de la recherche, HEC Montréal, 3000, chemin de la Côte-Sainte-Catherine, Montréal (Québec) Canada H3T $2 A 7$. 


\title{
R\&D Delegation in a Duopoly with Spillovers*
}

\author{
Désiré Vencatachellum** Bruno Versaevel ${ }^{\dagger}$
}

January 13, 2005

*We are indebted to Michèle Breton for her help in clarifying an important proof. We thank Etienne Billette de Villemeur, Martin Boyer, Robert Clark, Vianney Dequiedt and Laurent Flochel for helpful comments. Any remaining error is ours.

** Corresponding author. CIRANO and Institute of applied economics, HEC Montreal, Université de Montréal, 3000 Cote-Ste-Catherine, Montreal (Quebec) Canada H3T 2A7, Email: dv@hec.ca

${ }^{\dagger}$ GATE (UMR CNRS 5824) and EM Lyon, 23 Avenue Guy de Collongue, 69134 Ecully Cedex France, Email: versaevel@em-lyon.com 


\title{
R\&D Delegation in a Duopoly with Spillovers
}

\begin{abstract}
There is evidence that competing firms delegate $R \& D$ to the same independent profit-maximizing laboratory. We draw on this stylized fact to construct a model where two firms in the same industry offer transfer payments in exchange of user-specific R\&D services from a common laboratory. Interfirm and within-laboratory externalities affect the intensity of competition among delegating firms on the intermediate market for technology. Whether competition is relatively soft or tight is reflected by each firm's transfer payment offers to the laboratory. This in turn determines the laboratory's capacity to earn profits, R\&D outcomes, delegating firms' profits, and social welfare. We compare the delegated R\&D game to two other ones where firms (i) cooperatively conduct in-house $R \& D$, and (ii) non-cooperatively choose in-house R\&D. The delegated R\&D game Pareto dominates the other two games, and the laboratory earns positive profits, only if within-laboratory R\&D services are sufficiently complementary, but inter-firm spillovers are sufficiently low. We find no room for policy intervention, because the privately profitable decision to delegate $\mathrm{R} \& \mathrm{D}$, when the laboratory participates, always benefits consumers.
\end{abstract}

JEL Classification: C72; L13; O31.

Keywords: Research and Development, Externalities, Common agency. 


\section{Introduction}

There are many examples of firms delegating (i.e. outsourcing) R\&D to for-profit laboratories, and this is a growing phenomenon: contracted-out R\&D in the United States increased from approximately $\$ 6$ billion in 1997 to $\$ 15$ billion in 2000 (National Science Foundation 2003). ${ }^{1}$ More surprising is the fact that rival firms often delegate their R\&D to a common independent laboratory. For example, Bayer and ICI (two European firms in the chemical industry which compete on world markets) signed multi-year contracts in 1999 and 2000 respectively with Symyx, a U.S.-based private laboratory. Symyx receives payments by providing access to a proprietary technology for the production of high-value specialty polymers. Similarly, ThyssenKrupp and Arcelor (two major European steel suppliers), contracted in 1995 with VAI, a laboratory which specializes in the design of new steel production methods. The R\&D services received from VAI aim at producing wide thin strips of stainless and carbon steel directly from the molten metal, omitting the stages of slab casting and rolling.

Delegated R\&D contracts typically specify the required R\&D outcome in exchange of a payment scheme with detailed non-compete clauses or exclusivity conditions. ${ }^{2}$ For example, such clauses appear in a contract signed in 1997 by Millennium (a U.S.-based private laboratory in the biotechnology sector) and Monsanto (a US provider of agricultural products) for gene-sequencing R\&D services. In this contract, Millennium agrees not to share the benefits of this collaboration with any other agricultural enterprise without the prior written consent of Monsanto. Another example is a 1998 contract between the same laboratory and a pharmaceutical division of Bayer for the provision of molecules using genomics technology. The contract stipulates that the firm may not benefit from the outcomes of past collaborative research agreements between the laboratory and explicitly identified competitors, including Hoffmann-La Roche, Eli Lilly, and Pfizer. ${ }^{3}$

We draw from these stylized facts to construct a game where firms may delegate R\&D to an independent laboratory, or conduct in-house R\&D cooperatively or non-cooperatively. We allow firm- 
specific R\&D services to be either complements, substitutes, or independent inside the laboratory's R\&D cost function. We (i) ask when the laboratory earns positive profits, (ii) compare R\&D outcomes, firms' profits, and social welfare in a delegated game with those in cooperative and non-cooperative in-house $R \& D$ games, and (iii) derive conditions for $R \& D$ delegation to Pareto-dominate cooperative and non-cooperative R\&D.

While we know of no theoretical model of R\&D delegation to a common laboratory, even though such contracts are common, there is an extensive literature on the supply of technology licenses and in-house R\&D. The literature on licenses typically considers a monopolistic laboratory which sells a patented process innovation to vertically-related firms by making take-it-or-leave-it offers to downstream firms. Most analysis build on Katz and Shapiro's (1986) complete information model where the laboratory incurs no cost (i.e., $\mathrm{R} \& \mathrm{D}$ costs have been paid in a previous period), and each downstream firm is a potential user of one unit of the innovative input. ${ }^{4}$ These analysis base an inventor's ability to earn benefits on the strategic interaction among potential licensees.

The in-house R\&D literature pays particular attention to how technological spillovers affect R\&D outcomes, firms' profits, and social welfare, when firms may choose R\&D cooperatively or non-cooperatively. In their seminal analysis, d'Aspremont and Jacquemin (1988) consider duopolistic firms which invest in deterministic cost-reducing $R \& D$. They show that cooperation is $R \& D$ augmenting and welfare improving when between-firm technological spillovers are sufficiently high. The numerous extensions to their model assume in-house R\&D, either in each firm's separate laboratory or in a jointly owned one, with firms sharing the operating costs. ${ }^{5}$ Amir, Evstigneev and Wooders (2003) unify and generalize the results of this literature without relying on specific functional forms. They confirm two central results of this research stream: (i) R\&D cooperation increases firms' profits; and (ii) the profitability of $R \& D$ cooperation increases with the level of R\&D spillovers. ${ }^{6}$ 
As in d'Aspremont and Jacquemin (1988), we set up a model where two firms behave à la Cournot on a final market and benefit from cost-reducing R\&D outputs. We build on this benchmark framework by giving firms the option to delegate $\mathrm{R} \& \mathrm{D}$ non-cooperatively to an independent laboratory. As in Katz and Shapiro (1986), the laboratory is a profit-maximizer, and may serve none, one, or two firms. However, we abandon their assumption that the laboratory is in a monopolistic position inherited from past innovative efforts. Rather, we assume the laboratory responds to payment schemes by providing firm-specific R\&D services at some costs. ${ }^{7}$ This assumption captures situations where a laboratory derives income from tailor-made $\mathrm{R} \& \mathrm{D}$ which it provides to firms.

We consider that R\&D generates two externalities: (i) the usual between-firm cost-reducing technological spillovers, and (ii) positive or negative within-laboratory externalities depending on whether R\&D services are complements or substitutes. We refer to the first externalities as direct externalities and to the second as indirect ones. We allow firm-specific R\&D services to be either complements or substitutes in the laboratory, i.e. indirect externalities can be positive or negative respectively. ${ }^{8}$ We use the natural ability of a common agency framework to capture the antagonistic action of two forces: (i) the congruent objectives of the two users to share the resources of the same laboratory so as to benefit from economies of scale or scope, and (ii) the competing attempts by the same firms to drive the production of $R \& D$ services towards tailor-made outcomes. This allows us to isolate the effect of harmonized or conflicting requirements by $\mathrm{R} \& \mathrm{D}$ users, as a function of direct and indirect externalities, on the ability of the laboratory to earn benefits.

We establish a number of interesting and novel results. While one could expect the laboratory to always earn positive benefits when $R \& D$ services demanded by the firms are complements, we prove this is not the case. We find that the laboratory earns positive benefits only if the firm-specific R\&D services it produces are substitutable, or not too complementary, and inter-firm spillovers are sufficiently low. Intuitively, the ability of the laboratory to earn positive benefits depends on the degree of rivalry between the two firms for its services. This rivalry is a function of the degree of complementarity or 
substitutability of the research projects inside the laboratory (indirect externalities), and of spillovers (direct externalities). Whether competition for the laboratory's services is soft or tight is reflected by each firm's payment offers to the laboratory, and hence the laboratory's ability to earn excess benefits.

Equilibrium R\&D in the non-cooperative game is known to be lower (higher) than in the cooperative setting for low (high) direct spillovers (d'Aspremont and Jacquemin 1988). We show that R\&D is greater (smaller) in the delegated game than in the cooperative one for positive (negative) indirect spillovers. This occurs because the laboratory internalizes the strategic interaction of the two firms on the intermediate market for technology and on the final market for products via the payment schemes it receives. As a result the laboratory's choice of $R \& D$ is equivalent to it maximizing the sum of its benefits and the two firms' profits. In particular, zero within-laboratory externalities mean the equilibrium outcomes of the delegated $R \& D$ and cooperative $R \& D$ games are identical. When firms delegate $\mathrm{R} \& \mathrm{D}$, the complementarity of their research projects means that the laboratory can produce R\&D more efficiently than the firms. Hence, R\&D in the delegated game can exceed the non-cooperative solution even when direct externalities are negative - in which case $R \& D$ in the non-cooperative game exceeds that in the cooperative one - provided indirect externalities are sufficiently positive. For similar reasons delegated $R \& D$ may exceed the non-cooperative solution when direct externalities are positive provided indirect externalities are not too negative.

When firms delegate $R \& D$ to the laboratory, they earn higher profits as indirect externalities increase. This arises because (i) it is relatively cheaper for the laboratory to perform $\mathrm{R} \& \mathrm{D}$, than for firms to conduct it in house, as indirect externalities increase, while (ii) simultaneously the increased complementarity between the firms' R\&D services means they can reduce their transfer payments to the laboratory. We show that firms' profits are higher when they delegate R\&D to the laboratory, than in the other two organizational forms, for sufficiently high indirect externalities. However, for reasons given above, there is no guarantee that the laboratory will choose to operate at such high levels of indirect externalities. If the laboratory must earn positive benefits to participate, the firms 
choose to delegate R\&D only when direct externalities are low. This result differs sharply from the well established claim that R\&D cooperation (as opposed to delegation) becomes more profitable with increasingly high direct externalities.

The welfare analysis proceeds by observing that higher R\&D implies lower prices, more consumption, and consequently higher consumer surplus. We find that R\&D delegation Pareto-dominates cooperation and non-cooperation, and the laboratory earns positive benefits, if and only if R\&D services are sufficiently complementary inside the laboratory and inter-firm spillovers are sufficiently low. This occurs because (i) the laboratory operates only for sufficiently low indirect externalities, whereas (ii) firms earn higher profits and consumers obtain more surplus with delegated $R \& D$ than in the other two settings only for sufficiently high indirect externalities. This opposition prevents at least one of the parties (the laboratory, the firms, or consumers) to gain strictly more in the delegated $R \& D$ game than in the other two games when spillovers are too high. From a policy perspective, we prove that a firm's choice to delegate R\&D to an independent profit-making laboratory never harms consumers. Hence, there is no room for policy intervention when $R \& D$ delegation takes place along the lines described in this paper.

The present analysis complements papers on the industrial organization of $\mathrm{R} \& \mathrm{D}$, in the spirit of Aghion and Tirole (1994) and Ambec and Poitevin (2001), which examine the impact of nondeterministic R\&D on the relative efficiency of a separate governance structure (where a single user buys an innovation from an independent unit) and an integrated structure (in which the user sources R\&D internally). Both Aghion and Tirole (1994) and Ambec and Poitevin (2001) assume a unique R\&D user. We, on the other hand, are interested in the strategic interaction of several firms which not only contract with a common laboratory but also compete on the product market. ${ }^{9}$ Another more recent strand of the $R \& D$ literature analyzes cooperative $R \& D$ in vertically-related industries (Banerjee and Lin 2001, Banerjee and Lin 2003, Atallah 2002, Brocas 2003, Ishii 2004, for example). In these papers, firms may benefit from imperfectly appropriable process $R \& D$ produced not only by a direct 
competitor, but also by upstream or downstream firms. What is transacted by firms between successive stages of production is an homogeneous input to be transformed in some final good, not R\&D services. Although this framework is perfectly valid for some settings, the examples provided here concern the delegation of R\&D services.

The remainder of the paper is as follows. Section 2 presents the three R\&D games, defines and discusses the equilibrium concepts. Section 3 establishes that the laboratory maximizes aggregate benefits and derives conditions under which it earns zero benefits. Section 4 ranks the outcomes of the three R\&D games as a function of firm-level technological spillovers and within-laboratory spillovers, and illustrate the results graphically in the direct and indirect externalities plane. Next, section 5 investigates whether one of the three games can Pareto-dominate the other two and discusses policy implications. Finally, section 6 concludes. All proofs and figures are in the Appendix.

\section{R\&D Games}

We consider a duopoly which faces a linear inverse demand function:

$$
p_{i}(\mathbf{q})=a-b\left(q_{i}+\theta q_{j}\right)
$$

for $i, j=1,2, i \neq j$, where $\mathbf{q} \equiv\left(q_{i}, q_{j}\right) \in \mathrm{R}_{+}^{2}$ describes output quantities, $p_{i}$ is firm $i$ 's unit price, $a$ and $b$ are positive parameters, and $\theta \in[0,1]$ captures the degree of substitutability between the two products. Each firm incurs a constant unit cost of production which it can reduce through process innovations. We also assume, as in d'Aspremont and Jacquemin (1988), a unit cost of production:

$$
c_{i}(\mathbf{x})=c-x_{i}-\beta x_{j}
$$


for $i, j=1,2, i \neq j$, where $\mathbf{x} \equiv\left(x_{i}, x_{j}\right) \in R_{+}^{2}$ is the vector of R\&D outputs obtained by firms, the marginal cost parameter $c \in(0, a)$, and $\beta \in[0,1]$ denotes technological spillovers. It follows that firm $i$ 's gross profit function is:

$$
\pi_{i}(\mathbf{q}, \mathbf{x})=\left[p_{i}(\mathbf{q})-c_{i}(\mathbf{x})\right] q_{i}
$$

The next section formalizes three cost-reducing R\&D games in extensive forms.

\subsection{Cooperative $R \& D$}

In a first stage, the duopoly cooperatively chooses in-house R\&D outcomes in the two proprietary laboratories by maximizing joint profits. The cost of $R \& D$ is given by:

$$
r\left(x_{i}\right)=\frac{\gamma}{2} x_{i}^{2}
$$

for $i=1,2$, and where $\gamma$ is a positive parameter. In a second stage, given the chosen R\&D outcomes each firm non-cooperatively maximizes individual profits by choosing its output. In this game, we denote firm $i$ 's net profit, as a function of $\mathbf{x}$, by:

$$
\pi_{i}^{\mathrm{c}}(\mathbf{x}) \equiv \pi_{i}\left(\mathbf{q}^{\mathrm{c}}, \mathbf{x}\right)-r\left(x_{i}\right)
$$

where $\mathbf{q}^{\mathrm{c}} \equiv\left(q_{1}^{\mathrm{c}}(\mathbf{x}), q_{2}^{\mathrm{c}}(\mathbf{x})\right)$. Firms' symmetric net equilibrium profits are denoted by $\pi^{\mathrm{c}}$.

Definition 1 (NE) The symmetric final market outcome $\mathbf{q}^{\mathrm{c}}$ is a Nash equilibrium if:

$$
\pi_{i}\left(\mathbf{q}^{\mathrm{c}}, \mathbf{x}\right) \geq \pi_{i}\left(q_{i}, q_{j}^{\mathrm{c}}(\mathbf{x}), \mathbf{x}\right)
$$

all $\mathbf{x}$, all $q_{i}, i, j=1,2, i \neq j$. 
Instead of cooperatively choosing their $\mathrm{R} \& \mathrm{D}$, firms may decide to do so non-cooperatively, as explained below.

\subsection{Non-Cooperative R\&D}

In a first stage, firms non-cooperatively conduct $R \& D$ in-house by maximizing their individual profits in their own R\&D, with each firm's R\&D costs given by (4). The second stage is as in the cooperative $\mathrm{R} \& \mathrm{D}$ game. In this game, we denote firm $i$ 's net profit as a function of $\mathbf{x}$ by:

$$
\pi_{i}^{\mathrm{n}}(\mathbf{x}) \equiv \pi_{i}\left(\mathbf{q}^{\mathrm{n}}, \mathbf{x}\right)-r\left(x_{i}\right)
$$

where $\mathbf{q}^{\mathrm{n}} \equiv\left(q_{1}^{\mathrm{n}}(\mathbf{x}), q_{2}^{\mathrm{n}}(\mathbf{x})\right)$. Firms' symmetric net equilibrium profits are denoted by $\pi^{\mathrm{n}}$.

Definition 2 (SPNE) The symmetric equilibrium quantities and in-house $\mathrm{R} \& \mathrm{D}$ outcomes $\left(\mathbf{q}^{\mathrm{n}}, \mathrm{x}^{\mathrm{n}}\right)$ are a subgame-perfect Nash equilibrium if:

i) $\mathbf{q}^{\mathrm{n}}$ is a NE as in Definition 1, and

ii) $\mathbf{x}^{\mathrm{n}}$ is a NE, that is $\pi_{i}^{\mathrm{n}}\left(\mathbf{x}^{\mathrm{n}}\right) \geq \pi_{i}^{\mathrm{n}}\left(x_{i}, x_{j}^{\mathrm{n}}\right)$, for all $x_{i}, i, j=1,2, i \neq j$.

This game is identical to another one where, in lieu of in-house R\&D production, there are two independent laboratories. In that alternative game, each firm writes a contract with one exclusive laboratory to obtain specific R\&D services in exchange of transfer payments. In our complete information setup, it follows that a firm's problem is as in (7), but $r\left(x_{i}\right)$ is now firm $i$ 's payment for $x_{i}$, and the laboratory earns zero benefits. The problem is however different if there is a unique, common, and independent laboratory, from which the two firms buy R\&D services. We tackle this next. 


\subsection{Delegated R\&D}

In a first stage, the two firms (principals) simultaneously and non cooperatively purchase $x_{1}$ and $x_{2}$ by offering contingent transfer payments $t_{i}(\mathbf{x})$ to one common laboratory (an agent). In light of the examples given in the introduction, we let each firm's transfer be a function of $x_{1}$ and $x_{2}$. This captures the fact that real-world contracts include various non-compete clauses and property rights protections that subordinate payments to exclusivity conditions, as documented in introduction. Several explanations for the fact that buyers of new knowledge write contracts can be found in the literature. In a cross-sectorial empirical analysis, Veugelers (1997) remarks that when in-house facilities are available, as we assume in the present paper, the capacity to go for it alone increases a firm's bargaining power in negotiating with an external laboratory. On the intermediate market for biotechnology, where R\&D buyers are large pharmaceutical, agribusiness, or chemical firms, Lerner and Merges (1998) evoke the financial constraints faced by specialized laboratories, and Argyres and Liebeskind (2002) refer to a high rate of entry on the supply side.

For each firm, we denote the set of transfer payments by:

$$
T \equiv\{t \mid t(\mathbf{x}) \geq 0 \quad \text { for all } \quad \mathbf{x}\}
$$

In a second stage, given $\mathbf{t} \equiv\left(t_{1}, t_{2}\right)$, the laboratory chooses the amounts of firm-specific $\mathrm{R} \& \mathrm{D}$ services, at a cost $s(\mathbf{x})$, that maximize its benefit given by:

$$
\mathcal{L}(\mathbf{x})=t_{1}(\mathbf{x})+t_{2}(\mathbf{x})-s(\mathbf{x})
$$

We assume that the laboratory may choose to contract with no firm, in which case it earns zero benefits.

This leads to a participation constraint:

$$
\mathcal{L} \geq 0
$$


When discussing policy implications later, we shall consider situations where (10) holds with strict inequality. This would be the case if the laboratory incurs positive (arbitrarily small) installation costs, or faces a profitable outside option. We denote the set of R\&D services which, given strategies t, maximize the laboratory's benefits by:

$$
X(\mathbf{t}) \equiv \arg \max _{\mathbf{x}} \mathcal{L}(\mathbf{x}(\mathbf{t}))
$$

The third stage is as the final stage in the other two games.

To compare the delegation of $\mathrm{R} \& \mathrm{D}$ with the cooperative and non-cooperative cases of reference, we keep the assumption that information is complete among firms. However, this does not extend to the laboratory, which needs not know downstream cost and demand functions. An outcome of the delegated R\&D game is a three-tuple $\left(\mathbf{x}^{\mathrm{d}}, \mathbf{t}^{\mathrm{d}}, \mathbf{q}^{\mathrm{d}}\right)$, where $\mathbf{x}^{\mathrm{d}}$ denotes the laboratory's equilibrium choice, $\mathbf{t}^{\mathrm{d}}$ firms' equilibrium payments, and $\mathbf{q}^{\mathrm{d}}$ equilibrium quantities on the final market. In this game firm $i$ 's net profit, as a function of $\mathbf{x}$, equals:

$$
\pi_{i}^{\mathrm{d}}(\mathbf{x}) \equiv \pi_{i}\left(\mathbf{q}^{\mathrm{d}}, \mathbf{x}\right)-t_{i}^{\mathrm{d}}(\mathbf{x})
$$

where $\mathbf{q}^{\mathrm{d}} \equiv\left(q_{1}^{\mathrm{d}}(\mathbf{x}), q_{2}^{\mathrm{d}}(\mathbf{x})\right)$. The laboratory bears all R\&D costs, while the functional form of firms' net profits in the delegated R\&D game is similar to Crémer and Riordan (1987) who model multilateral transactions with bilateral contracts, but with transfer payments that are here contingent on the laboratory's choice of R\&D outputs. Firms' symmetric net equilibrium profits are denoted by $\pi^{\mathrm{d}}$.

Definition 3 (TSPNE) The symmetric equilibrium delegated R\&D outcomes, transfer payments, and equilibrium quantities $\left(\mathbf{x}^{\mathrm{d}}, \mathbf{t}^{\mathrm{d}}, \mathbf{q}^{\mathrm{d}}\right)$ are a truthful subgame-perfect Nash equilibrium if:

i) $\mathbf{q}^{\mathrm{d}}$ is a NE as in Definition 1, 
ii) $\left(\mathbf{x}^{\mathrm{d}}, \mathbf{t}^{\mathrm{d}}\right)$ is a NE, that is $\mathbf{x}^{\mathrm{d}} \in X\left(\mathbf{t}^{\mathrm{d}}\right)$ and there is no $i=1,2, t_{i} \in T$, and no $\mathbf{x} \in X\left(t_{i}, t_{j}^{\mathrm{d}}\right)$ such that $\pi_{i}^{\mathrm{d}}(\mathbf{x})>\pi_{i}^{\mathrm{d}}\left(\mathbf{x}^{\mathrm{d}}\right)$, and

iii) $t_{i}^{\mathrm{d}}$ is truthful relative to $\mathbf{x}^{\mathrm{d}}$, that is for all $\mathbf{x}$ either $\pi_{i}^{\mathrm{d}}(\mathbf{x})=\pi_{i}^{\mathrm{d}}\left(\mathbf{x}^{\mathrm{d}}\right)$, or $\pi_{i}^{\mathrm{d}}(\mathbf{x})<\pi_{i}^{\mathrm{d}}\left(\mathbf{x}^{\mathrm{d}}\right)$ and $t_{i}^{\mathrm{d}}(\mathbf{x})=0, i, j=1,2, i \neq j$.

Intuitively, in any truthful equilibrium, a firm offers a transfer $t_{i}^{\mathrm{d}}(\mathbf{x})$ that exactly reflects its individual valuation of the laboratory's choice of $\mathbf{x}$ with respect to $\mathbf{x}^{\mathrm{d}}$, all $\mathbf{x}$. Definition 3 -iii) refers to two possible cases. Either gross profits $\pi_{i}\left(\mathbf{q}^{\mathrm{d}}(\mathbf{x}), \mathbf{x}\right)$ exceed net equilibrium profits $\pi_{i}\left(\mathbf{q}^{\mathrm{d}}\left(\mathbf{x}^{\mathrm{d}}\right), \mathbf{x}^{\mathrm{d}}\right)-t_{i}^{\mathrm{d}}\left(\mathbf{x}^{\mathrm{d}}\right)$, and the difference between transfer offers $t_{i}^{\mathrm{d}}\left(\mathbf{x}^{\mathrm{d}}\right)$ and $t_{i}^{\mathrm{d}}(\mathbf{x})$ is set equal to the difference between gross profits $\pi_{i}\left(\mathbf{q}^{\mathrm{d}}\left(\mathbf{x}^{\mathrm{d}}\right), \mathbf{x}^{\mathrm{d}}\right)$ and $\pi_{i}\left(\mathbf{q}^{\mathrm{d}}(\mathbf{x}), \mathbf{x}\right)$. Or principal $i$ 's gross profits with $\mathbf{x}$ are strictly less than net equilibrium profits obtained with $\left.\mathbf{x}^{\mathrm{d}}\right)$, in which case the transfer $t_{i}^{\mathrm{d}}(\mathbf{x})$ is set to zero.

For this game, as in Laussel and Le Breton (2001), by equilibria we mean truthful subgame-perfect Nash equilibria, and we recall two properties that justify the choice of this solution concept. Firstly, for any set of transfer offers by any one of the two firms, there exists a truthful strategy in the other firm's best-response correspondence. This existence property implies that a firm can restrict itself to truthful strategies. Secondly, all truthful Nash equilibria are coalition-proof. This stability property says that total net profits, as obtained in a truthful subgame-perfect equilibrium by the two firms, are higher than in any other subgame-perfect Nash equilibria. The two properties hold for all given choices of $\mathbf{q}$ in the final stage, including $\mathbf{q}^{\mathrm{d}} \cdot{ }^{10}$

For the sake of tractability we specify a laboratory's cost function as follows:

$$
s(\mathbf{x})=\frac{\gamma}{2}\left(x_{1}^{2}+x_{2}^{2}\right)-\delta x_{1} x_{2}
$$

for $i=1,2$ and $i \neq j$, and $\delta \in[-\gamma, \gamma)$ captures complementary (substitutable) R\&D services in the laboratory if $\delta>0(\delta<0)$. If $\delta=0$, the laboratory is as efficient as each firm's proprietary laboratory. 
Note that the term $\delta x_{1} x_{2}$ in (13) is the simplest way to capture complementarity or substitutability between two variables. A nice aspect of this formalization is that complementarity or substitutability is reflected by the sign a single parameter as suggested by Milgrom and Roberts (1990, p. 517) in an illustrative example. The same algebraic specification appears in the complete information version of the cost function of a common agent in Martimort and Stole (2003a), and in the utility function of a common agent in Martimort and Stole (2003b). The existence of within-laboratory spillovers gives rise to indirect externalities, which are defined, and contrasted with between-firm technological spillovers, below.

\subsection{Direct and Indirect Externalities}

Define firm $i$ 's concentrated profits as $\pi_{i}(\mathbf{x}) \equiv \pi(\mathbf{q}(\mathbf{x}), \mathbf{x})$. In all three games, concentrated profits vary with technological spillovers which are captured by $\beta$. These spillovers are a direct externality because firm $i$ 's gross profits not only depend on $x_{i}$, but also on $x_{j}$ for all $\beta>0$. These externalities are negative (positive) if an increase in $x_{j}$ has a negative (positive) impact on firm $i$ 's concentrated profits.

Property 1 (Direct Externalities) For $i, j=1,2$, and $i \neq j$

$$
\frac{\mathrm{d} \pi_{i}(\mathbf{x})}{\mathrm{d} x_{j}} \underset{<}{=} 0 \text { if and only if } \beta \underset{<}{>} \theta / 2
$$

In what follows, we identify positive (negative) direct externalities with $\beta>(<) \theta / 2$.

As for indirect externalities, they appear only in the delegated R\&D game where the laboratory's choice of $x_{i}$ affects the costs of providing $x_{j}$, with $i \neq j$. Indirect externalities are negative (positive) if serving higher quantities to a firm makes it more (less) costly for the laboratory to serve the other one, i.e. if the production of R\&D services are substitutable (complementary). More formally: 
Property 2 (Indirect Externalities) For $i, j=1,2$, and $i \neq j$

$$
\frac{\mathrm{d} s(\mathbf{x})}{\mathrm{d} x_{i} \mathrm{~d} x_{j}} \underset{>}{>} 0 \text { if and only if } \delta \stackrel{>}{=} \underset{<}{<}
$$

Typically, R\&D services are complements (i.e., $\delta>0$ ) when the laboratory can serve the two firms by using the same resources. They are substitutes (i.e., $\delta<0$ ) when there are bottlenecks in the laboratory's capacity to simultaneously supply the two firm-specific services.

We now establish how the laboratory's choice compares with the cooperative game. We then derive a condition under which the laboratory earns positive benefits. This condition partitions the $(\beta, \gamma)$ space, which we refer to as the externalities plane in the remainder of the paper.

\section{Profits Maximization and Distribution}

Let the aggregate benefits function for the two firms and the laboratory be:

$$
\Lambda(\mathbf{x})=\pi_{1}^{\mathrm{d}}(\mathbf{x})+\pi_{2}^{\mathrm{d}}(\mathbf{x})-s(\mathbf{x})
$$

Proposition 1 (Joint Profits Maximization) In all TSPNE, the laboratory's choice of R\&D services to maximize its benefits (9) is equivalent to maximizing aggregate benefits (14).

Proposition 1 is a restatement of Bernheim and Whinston (1986) adapted to our context. It says that the non-cooperative attempt by firms to maximize individual profits by delegating R\&D leads to a choice of $\mathbf{x}$ that maximizes the aggregate benefits of all parties, including the laboratory. By maximizing the sum of the two firms profits, net of R\&D costs, the laboratory internalizes both direct and indirect externalities. However, Proposition 1 is silent on consumers' welfare. We will be able to 
address this issue once we compute the quantities of $R \& D$ services produced by the laboratory and compare them to the two other games. This is the subject of section 4.1.

Denote by $\Lambda$ the maximum aggregate benefits obtained by maximizing (14) with respect to $\mathbf{x}$. The following proposition characterize

Proposition 2 (Joint Profits Distribution) There exists a continuous strictly decreasing frontier in the externalities plane $(\beta, \delta)$, denoted by $\delta_{\mathcal{L}=0}$, and which includes the point $(\theta / 2,0)$, such that in all TSPNE the laboratory earns positive benefits if $\delta<\delta_{\mathcal{L}=0}$, and exactly breaks even otherwise.

Proposition 2 says that the magnitude of indirect externalities $(\delta)$, for a given value of direct externalities $(\beta)$, determines the laboratory's ability to appropriate a share of innovation benefits, and thus laboratory's participation constraint (10) to be slack or binding. This is because indirect externalities, in combination with technological spillovers, impact the nature of competition between the two firms on the intermediate market for R\&D. This competition is reflected by their offers of transfer payments $\left(t_{1}^{\mathrm{d}}(\mathbf{x}), t_{2}^{\mathrm{d}}(\mathbf{x})\right)$. On the one hand, if both externalities are negative, a firm's concentrated profits decrease with the other firm's R\&D (Property 1), and serving one firm increases the laboratory's cost of serving the other (Property 2). This is a case of tough competition between the two firms for the laboratory's services, which is a source of positive profits for it. On the other hand, if both externalities are positive, a firm's concentrated profits are increasing in the other firm's $R \& D$, and serving one firm decreases the laboratory's cost of serving the other. Thus, competition for the laboratory's resources is relatively soft and the laboratory earns no benefits. When the externalities are of opposite signs, the laboratory's ability to appropriate benefits depends on their magnitudes. This opposition gives rise to $\delta_{\mathcal{L}=0}$, which can thus be viewed as a weighted sum of direct and indirect externalities.

Propositions 1 and 2 are useful for the comparison of the three R\&D games outcomes at the pivotal no-externalities point $(\beta, \delta)=(\theta / 2,0)$. 
Proposition 3 (The No-Externalities Case) The outcomes of the three games are the same at the pivotal no-externalities point.

At the pivotal point, there are no direct and indirect externalities. This implies that solutions in $\mathbf{x}$ are the same in the three R\&D games. In the delegated game the laboratory earns zero benefits, as if firms were relying on in-house $\mathrm{R} \& \mathrm{D}$ capabilities, because $(\beta, \delta)=(\theta / 2,0)$ is on $\delta_{\mathcal{L}=0}$. We now solve the three R\&D games by backward induction and rank the performance of the three games in the externalities plane. The explicit solutions of the games are in Appendix A.

\section{Comparing the Three Games}

We partition the externalities plane by deriving frontiers on which $R \& D$, profits, or welfare are equal in the delegated $R \& D$ game and in one of the two alternative games. By welfare, we mean the sum of consumer surplus, firms' profits, and the laboratory's benefits. For the sake of completeness, we also include the comparison of the outcomes of the cooperative and non-comparative games as established by d'Aspremont and Jacquemin (1988). Note from the onset that, as a result of Proposition 3 all such frontiers include the pivotal no-externalities point.

\subsection{R\&D outcomes}

\section{Lemma 1 (Cooperative, Non-Cooperative, and Delegated R\&D)}

i) There exists a continuous frontier $\delta_{x^{\mathrm{d}}=x^{\mathrm{c}}}$ in the externalities plane such that in all TSPNE $x^{\mathrm{d}} \gtreqless x^{\mathrm{c}}$ if and only if $\delta \underset{<}{\gtrless} \delta_{x^{\mathrm{d}}=x^{\mathrm{c}}}$, with

$$
\begin{aligned}
& \delta_{\mathcal{L}=0}>\delta_{x^{\mathrm{d}}=x^{\mathrm{c}}}=0 \quad \text { for } \quad \beta<\theta / 2 ; \\
& \delta_{\mathcal{L}=0}=\delta_{x^{\mathrm{d}}=x^{\mathrm{c}}}=0 \quad \text { for } \quad \beta=\theta / 2 ;
\end{aligned}
$$




$$
\delta_{\mathcal{L}=0}<\delta_{x^{\mathrm{d}}=x^{\mathrm{c}}}=0 \quad \text { for } \quad \beta>\theta / 2 .
$$

ii) There exists a continuous frontier $\delta_{x^{\mathrm{d}}=x^{\mathrm{n}}}$ in the externalities plane, such that in all TSPNE $x^{\mathrm{d}} \underset{<}{\gtrless} x^{\mathrm{n}}$ if and only if $\delta \underset{<}{\gtrless} \delta_{x^{\mathrm{d}}=x^{\mathrm{n}}}$, with

$$
\begin{array}{lll}
0<\delta_{x^{\mathrm{d}}=x^{\mathrm{n}}}<\delta_{\mathcal{L}=0} & \text { for } & \beta<\theta / 2 ; \\
\delta_{\mathcal{L}=0}=\delta_{x^{\mathrm{d}}=x^{\mathrm{n}}}=0 & \text { for } & \beta=\theta / 2 ; \\
0>\delta_{x^{\mathrm{d}}=x^{\mathrm{n}}}>\delta_{\mathcal{L}=0} & \text { for } & \beta>\theta / 2 .
\end{array}
$$

Direct and indirect externalities combine to give Lemma 1. First consider Lemma 1- $(i)$. The cooperative and delegated games yield the same R\&D solution when there are no indirect externalities because of Proposition 1 (which says that the laboratory maximizes aggregate benefits in equilibrium), and of Property 2 (which implies that costs are the same in both games when $\delta=0$ ). We know that the independent laboratory is more (less) efficient than in-house laboratories when indirect externalities are positive (negative), that is when $\delta>0(\delta<0)$. This completes the partitioning of the externalities plane for R\&D output in the two games under scrutiny.

Second, consider Lemma 1-(ii). Recall that, from Property 1, optimal R\&D is greater (smaller) in the cooperative than in the non-cooperative game for positive (negative) direct externalities. Let direct externalities be positive. If indirect externalities are also positive, the laboratory's higher efficiency means that delegated $R \& D$ exceeds the cooperative, and hence the non-cooperative, solutions. If indirect externalities are negative, the laboratory is at a disadvantage in the production of R\&D over in-house laboratories. However, as it internalizes inter-firm direct externalities via the transfer payments it receives, it is only for sufficiently negative indirect externalities that non-cooperative $R \& D$ exceeds the delegated game solution. Consequently, $\delta_{x^{\mathrm{d}}=x^{\mathrm{n}}}$ must cross in the South-East quadrant of the externalities plane. 
Now let direct externalities be negative. If indirect externalities are also negative, the laboratory's lower efficiency than in-house laboratories means that the delegated solution is smaller than the cooperative, and by transitivity of the non-cooperative one also. However, as the laboratory gains in efficiency as $\delta$ increases, there exist sufficiently high positive indirect externalities for the R\&D outcome under the delegated game to exceed that under the non-cooperative game. Hence $\delta_{x^{\mathrm{d}}=x^{\mathrm{n}}}$ must lie in the North-West quadrant of the externalities plane.

\section{[Insert figure 1 about here]}

The juxtaposition of $\delta_{x^{\mathrm{d}}=x^{\mathrm{c}}}$ and $\delta_{x^{\mathrm{d}}=x^{\mathrm{n}}}$ in the externalities plane, as illustrated in Figure 1, allows us to rank optimal $R \& D$ across the three games. It is of interest that optimal $R \& D$ in the delegated game is greater than in either of the two games for sufficiently high indirect externalities, even when direct externalities are negative. This result stands in contrast with cooperative $R \& D$ always being less than non-cooperative one for negative direct externalities.

\subsection{Firms' Profits}

\section{Lemma 2 (Cooperative, Non-Cooperative, and Delegated Profits)}

i) There exists a continuous frontier $\delta_{\pi^{\mathrm{d}}=\pi^{\mathrm{c}}}$ in the externalities plane such that in all TSPNE $\pi^{\mathrm{d}} \underset{<}{\gtrless} \pi^{\mathrm{c}}$ if and only if $\delta \underset{<}{\gtrless} \delta_{\pi^{\mathrm{d}}=\pi^{\mathrm{c}}}$, with

$$
\begin{array}{lll}
0<\delta_{\pi^{\mathrm{d}}=\pi^{\mathrm{c}}}<\delta_{\mathcal{L}=0} & \text { for } & \beta<\theta / 2 ; \\
\delta_{\pi^{\mathrm{d}}=\pi^{\mathrm{c}}}=\delta_{\mathcal{L}=0}=0 & \text { for } & \beta=\theta / 2 ; \\
0=\delta_{\pi^{\mathrm{d}}=\pi^{\mathrm{c}}}>\delta_{\mathcal{L}=0} & \text { for } & \beta>\theta / 2 .
\end{array}
$$


ii) There exists a continuous frontier $\delta_{\pi^{\mathrm{d}}=\pi^{\mathrm{n}}}$ in the externalities plane such that in all TSPNE $\pi^{\mathrm{d}} \underset{<}{\gtrless} \pi^{\mathrm{n}}$ if and only if $\delta \underset{<}{\gtrless} \delta_{\pi^{\mathrm{d}}=\pi^{\mathrm{n}}}$, with

$$
\begin{array}{lll}
0<\delta_{x^{\mathrm{d}}=x^{\mathrm{n}}}<\delta_{\pi^{\mathrm{d}}=\pi^{\mathrm{n}}}<\delta_{\pi^{\mathrm{d}}=\pi^{\mathrm{c}}} & \text { for } & \beta<\theta / 2 ; \\
\delta_{x^{\mathrm{d}}=x^{\mathrm{n}}}=\delta_{\pi^{\mathrm{d}}=\pi^{\mathrm{n}}}=\delta_{\pi^{\mathrm{d}}=\pi^{\mathrm{c}}}=0 & \text { for } & \beta=\theta / 2 ; \\
0=\delta_{\pi^{\mathrm{d}}=\pi^{\mathrm{c}}}>\delta_{\pi^{\mathrm{d}}=\pi^{\mathrm{n}}}>\delta_{x^{\mathrm{d}}=x^{\mathrm{n}}} & \text { for } & \beta>\theta / 2 .
\end{array}
$$

The intuition for $\delta_{\pi^{\mathrm{d}}=\pi^{\mathrm{c}}}$ follows also from how the two externalities combine. For the same reasons as in Section 4.1, aggregate benefits are ceteris paribus increasing in indirect externalities. However, when part of the aggregate benefits accrue to the laboratory, which is the case for $\delta<\delta_{\mathcal{L}=0}$, then indirect externalities must be sufficiently positive to generate enough surplus to compensate for the laboratory's benefits. Hence, if direct externalities are negative, the locus which equalizes firms' profits in the delegated and cooperative games must lie in the North-West quadrant of the externalities plane. It cannot however lie above $\delta_{\mathcal{L}=0}$ where aggregate benefits in the delegated game exceed those in the cooperative game, but are divided equally between the two firms. If direct externalities are positive, the frontier is confounded with $\delta=0$ because of Proposition 1, the cost structure being the same in both games and the laboratory earning zero benefits.

The intuition for the $\delta_{\pi^{\mathrm{d}}=\pi^{\mathrm{n}}}$ locus is as follows. Recall that a firm's profits in the cooperative game always exceed those under the non-cooperative one because cooperation internalizes direct externalities and prevents R\&D duplication. As a firm's profits in both the cooperative and delegated games are equal along $\delta_{\pi^{\mathrm{d}}=\pi^{\mathrm{c}}}$, by transitivity delegated profits exceed non-cooperative ones along that locus. Consider negative direct externalities. For $\delta=0$, along that line cooperative profits are greater than those obtained in the delegated game. However, firms' profits in the delegated game are increasing in 
indirect externalities (Lemma D-2 in Appendix D). Hence, there exists a unique decreasing continuous locus in the North-West quadrant of Figure 2 such that $\pi^{\mathrm{d}}=\pi^{\mathrm{n}}$.

By the same token, there must exist a locus in the South-East quadrant of Figure 2 which equalizes profits in the delegated and non-cooperative games. That locus must lie below $\delta_{x^{\mathrm{d}}=x^{\mathrm{n}}}$ for the following reason. Along $\delta_{x^{\mathrm{d}}=x^{\mathrm{n}}}$ optimal $\mathrm{R} \& \mathrm{D}$ expenditures are equal in both the delegated and non-cooperative games. However, the laboratory is less efficient than in-house R\&D when there are negative indirect externalities. It follows that aggregate benefits in the non-cooperative game exceed those in the delegated game along that locus. As the laboratory does not earn negative profits, $\pi^{\mathrm{d}}<\pi^{\mathrm{n}}$ along $\delta_{x^{\mathrm{d}}=x^{\mathrm{n}}}$. Therefore $\delta_{\pi^{\mathrm{d}}=\pi^{\mathrm{n}}}$ lies above $\delta_{x^{\mathrm{d}}=x^{\mathrm{n}}}$.

\section{[Insert figure 2 about here]}

Figure 2 graphs $\delta_{\pi^{\mathrm{d}}=\pi^{\mathrm{c}}}$ and $\delta_{\pi^{\mathrm{d}}=\pi^{\mathrm{n}}}$ to compare firms' profits in the three games. As expected, firms' profits are highest in the delegated game when both externalities are positive. However, delegated R\&D may yield the lowest profits even if direct externalities are weakly negative and indirect externalities are weakly positive (region below $\delta_{\pi^{\mathrm{d}}=\pi^{\mathrm{n}}}$ in Figure 2). This occurs because in that region the laboratory earns positive benefits and indirect externalities do not have a high enough impact on aggregate benefits. Hence, positive indirect externalities are necessary but not sufficient for firms to prefer the delegated game to the other two. Note that the firms' profits results have a benchmark flavor, in the sense that the net benefits obtained by a laboratory endowed with some informational advantage, would be bounded from below by the equilibrium benefits obtained here. 


\subsection{Welfare}

\section{Lemma 3 (Cooperative, Non-Cooperative, and Delegated Welfare)}

i) There exists a continuous frontier $\delta_{w^{\mathrm{d}}=w^{\mathrm{c}}}$ in the externalities plane such that in all TSPNE $w^{\mathrm{d}} \gtreqless w^{\mathrm{c}}$ if and only if $\delta \stackrel{\gtrless}{<} \delta_{w^{\mathrm{d}}=w^{\mathrm{c}}}$, with

$$
\begin{array}{lll}
0=\delta_{w^{\mathrm{d}}=w^{\mathrm{c}}}<\delta_{\mathcal{L}=0} & \text { for } & \beta<\theta / 2 ; \\
0=\delta_{w^{\mathrm{d}}=w^{\mathrm{c}}}=\delta_{\mathcal{L}=0} & \text { for } & \beta=\theta / 2 ; \\
0=\delta_{w^{\mathrm{d}}=w^{\mathrm{c}}}>\delta_{\mathcal{L}=0} & \text { for } & \beta>\theta / 2 .
\end{array}
$$

ii) There exists a continuous frontier $\delta_{w^{\mathrm{d}}=w^{\mathrm{n}}}$ in the externalities plane such that in all TSPNE $w^{\mathrm{d}} \gtreqless w^{\mathrm{n}}$ if and only if $\delta \underset{<}{\gtrless} \delta_{w^{\mathrm{d}}=w^{\mathrm{n}}}$, with

$$
\begin{array}{lll}
0<\delta_{w^{\mathrm{d}}=w^{\mathrm{n}}}<\delta_{x^{\mathrm{d}}=x^{\mathrm{n}}}<\delta_{\pi^{\mathrm{d}}=\pi^{\mathrm{n}}} & \text { for } & \beta<\theta / 2 ; \\
\delta_{w^{\mathrm{d}}=w^{\mathrm{n}}}=\delta_{x^{\mathrm{d}}=x^{\mathrm{n}}}=\delta_{\pi^{\mathrm{d}}=\pi^{\mathrm{n}}}=0 & \text { for } & \beta=\theta / 2 ; \\
0>\delta_{\pi^{\mathrm{d}}=\pi^{\mathrm{n}}}>\delta_{w^{\mathrm{d}}=w^{\mathrm{n}}}>\delta_{x^{\mathrm{d}}=x^{\mathrm{n}}} & \text { for } & \beta>\theta / 2 .
\end{array}
$$

The frontier $\delta_{w^{\mathrm{d}}=w^{\mathrm{c}}}$ is the direct consequence of Property 2, Proposition 1, and aggregate benefits being increasing in indirect externalities. To understand the intuition for $\delta_{w^{\mathrm{d}}=w^{\mathrm{n}}}$, let direct externalities be negative (i.e., $\beta<\theta / 2$ ). If $\delta=0$ in that region, both optimal $\mathrm{R} \& \mathrm{D}$ and firms' profits in the delegated game are smaller than in the non-cooperative game by Lemmas 1-(ii) and 2-(ii) respectively. Therefore, when indirect externalities are negative, $w^{\mathrm{d}}<w^{\mathrm{n}}$ along $\delta=0$. Second, aggregate benefits in the delegated game must be greater than in the non-cooperative game along $\delta_{x^{\mathrm{d}}=x^{\mathrm{n}}}$ because the laboratory is more efficient than in-house $R \& D$ facilities, and by definition the same amount of $R \& D$ is performed in both games. Moreover, $w^{\mathrm{d}}$ is increasing in $\delta$ (see Lemma D-3 in Appendix D). It follows 
that for each $\beta$ in the region bounded by $\delta=0$ and $\delta_{x^{\mathrm{d}}=x^{\mathrm{n}}}$, there exists a value for $\delta$ such that welfare in the delegated and non-cooperative games are equal. The existence of $\delta_{w^{\mathrm{d}}=w^{\mathrm{n}}}$ in the South-East quadrant of the externalities plane can be rationalized in the same way.

\section{[Insert figure 3 about here]}

\section{Pareto Optimal R\&D Organization and Policy Discussion}

The juxtaposition of Proposition 2, Lemmas 1, 2 and 3 in the externalities plane allows us to investigate whether one of the three games can Pareto-dominate the other two.

Theorem 1 The frontiers established in Proposition 2 and Lemmas 1, 2 and 3 are such that:

$$
\begin{aligned}
& \delta_{\mathcal{L}=0}>\delta_{\pi^{\mathrm{d}}=\pi^{\mathrm{c}}}>\delta_{\pi^{\mathrm{d}}=\pi^{\mathrm{n}}}>\delta_{x^{\mathrm{d}=x^{\mathrm{n}}}}>\delta_{w^{\mathrm{d}=w^{\mathrm{n}}}}>\delta_{w^{\mathrm{d}}=w^{\mathrm{c}}}=\delta_{x^{\mathrm{d}}=x^{\mathrm{c}}}=0 \quad \text { for } 0 \leq \beta<\theta / 2 ; \\
& \delta_{\mathcal{L}=0}=\delta_{\pi^{\mathrm{d}=\pi^{\mathrm{c}}}}=\delta_{\pi^{\mathrm{d}}=\pi^{\mathrm{n}}}=\delta_{x^{\mathrm{d}}=x^{\mathrm{n}}}=\delta_{w^{\mathrm{d}}=w^{\mathrm{n}}}=\delta_{w^{\mathrm{d}}=w^{\mathrm{c}}}=\delta_{x^{\mathrm{d}=x^{\mathrm{c}}}}=0 \quad \text { for } \beta=\theta / 2 ; \\
& 0=\delta_{x^{\mathrm{d}}=x^{\mathrm{c}}}=\delta_{\pi^{\mathrm{d}}=\pi^{\mathrm{c}}}=\delta_{w^{\mathrm{d}}=w^{\mathrm{c}}}>\delta_{\pi^{\mathrm{d}}=\pi^{\mathrm{n}}}>\delta_{w^{\mathrm{d}}=w^{\mathrm{n}}}>\delta_{x^{\mathrm{d}}=x^{\mathrm{n}}}>\delta_{\mathcal{L}=0} \quad \text { for } \theta / 2<\beta \leq 1 .
\end{aligned}
$$

All frontiers are defined on $[-\gamma, \gamma)$, and the fact they intersect for $\beta=\theta / 2$ stems from Proposition

3. For $(\beta, \delta)$ such that $0 \leq \beta<\theta / 2$ and $\delta_{\mathcal{L}=0}<\delta<\delta_{\pi^{\mathrm{d}}=\pi^{\mathrm{c}}}$, the laboratory earns positive benefits (as opposed to zero profits otherwise). Moreover, in that region, consumer surplus (as inferred from R\&D outcomes), and firms' equilibrium profits, are strictly higher in the delegated game than in the equilibria of cooperative and non-cooperative games. This does not hold elsewhere in the externalities plane, as can be checked from (15).

Corollary 1 (Delegation Dominance) The delegated R\&D game Pareto dominates the other two games, and the laboratory earns positive profits, for $0 \leq \beta<\theta / 2$ and $\delta_{\pi^{\mathrm{d}}=\pi^{\mathrm{c}}}<\delta<\delta_{\mathcal{L}=0}$. 
We have therefore established that for certain levels of externalities, consumers, firms, and the laboratory all benefit from the delegation of $R \& D$. Therefore, delegated $R \& D$ is a Pareto optimal organizational form. For simple reasons, this cannot occur when direct and indirect externalities are positive. In that case, the delegated game yields the highest profits and consumer surplus, but the laboratory earns no benefits because firms' interests are congruent. For opposite reasons, welfare is minimized under the delegated game if both direct and indirect externalities are sufficiently negative, although in this case a laboratory would earn positive profits. What is crucial for the delegated R\&D game to Pareto dominate the other two games, is that indirect externalities must not be too high, so that the firms must still compete for the laboratory's resources, which thus earns positive benefits and participates. But indirect externalities must be high enough to make welfare greater than in the other two games, and let firms obtain more of it than under the two other options.

\section{[Insert figure 4 about here]}

We can now use these results to examine when the interests of firms and consumers conflict or coincide. This is an important question because firms decide to delegate R\&D only if it is profitable for them to do so, and if the laboratory participates. We find that, although no one asks for consumers' consent, firms' privately profitable decision to delegate $R \& D$ is always socially optimal. To see that, remark first that in all three games consumer surplus increases with R\&D because lower costs lead to higher quantities and lower prices (see Appendix D-3). Second, in the externalities plane, for all values of direct spillovers, firms find it more profitable to delegate $R \& D$ than to do $R \& D$ in-house either cooperatively or non-cooperatively if and only if $\delta$ is above $\delta_{\pi^{\mathrm{d}}=\pi^{\mathrm{c}}}$ (Theorem 1 ). Now remark that $\delta_{\pi^{\mathrm{d}}=\pi^{\mathrm{c}}}$ is the "highest" profit frontier and that it is also always above the two frontiers $\delta_{x^{\mathrm{d}}=x^{\mathrm{c}}}$ and $\delta_{x^{\mathrm{d}}=x^{\mathrm{n}}}$ which allow us to compare the consumer surpluses obtained in all three games equilibria (see Figures 1 and 2). Hence, firms never find it profitable to delegate R\&D with consumers being worse 
off than in either of the two other games (as would be the case if we had, say, $\delta_{\pi^{\mathrm{d}}=\pi^{\mathrm{c}}}<\delta_{x^{\mathrm{d}}=x^{\mathrm{c}}}$ for some values of $\beta$ ).

A more striking result is obtained when the laboratory must earn strictly positive profits to participate (i.e., (10) is replaced by $\mathcal{L}>0$ ). This occurs if the laboratory has an outside option where it can earn some arbitrarily small positive net benefits. In that case, firms delegate $\mathrm{R} \& \mathrm{D}$ only if $\delta$ is between $\delta_{\pi^{\mathrm{d}}=\pi^{\mathrm{c}}}$ and $\delta_{\mathcal{L}=0}$ when direct externalities are negative (i.e., $0 \leq \beta<\theta / 2$ ). They cannot rely on the laboratory's $R \& D$ services when direct externalities are positive (i.e. $\theta / 2<\beta \leq 1$ ) because the frontier above which the laboratory earns zero benefits $\left(\delta_{\mathcal{L}=0}\right)$ lies below all the other frontiers in that region (see Figure 2). Consequently, when the laboratory must make positive benefits to participate, firms will profitably delegate R\&D services only when externalities fall in the Pareto dominating region defined in Corollary 1 and which corresponds to the shaded area in Figure 4. A straightforward policy implication is that, when firms behave as described here, there is no motivation for a regulator to constrain firms' choice to delegate R\&D.

\section{Conclusion}

R\&D outsourcing (delegation) is an increasingly important phenomenon, and many rivals delegate R\&D to a common independent laboratory. While many theoretical industrial organization models compare the outcomes of firms doing R\&D cooperatively or non-cooperatively, none has, to the best of our knowledge, investigated R\&D delegation in a formal setup and compared the three modes of R\&D. This paper fills that gap by setting up a simple model where competitors can independently choose to delegate R\&D to a profit-maximizing laboratory.

Our model of delegated R\&D builds on the literature where a firm's R\&D reduces not only its unit cost of production but also that of its competitor through technological spillovers (direct externalities). The R\&D projects which firms delegate to the laboratory give rise to an additional externality because 
they can be complements (positive indirect externalities), substitutes (negative indirect externalities), or independent. Positive (negative) indirect externalities can be associated with economies of scope (a congestion) in the production of $\mathrm{R} \& \mathrm{D}$. We characterize the impact of these two externalities on delegated R\&D outcomes, firms' profits, social welfare, and the laboratory's benefits. We compare the outcomes of delegated $R \& D$ to an independent profit-maximizing laboratory to firms doing in-house R\&D either non-cooperatively or cooperatively. One interesting aspect of our analysis is the ability to illustrate the results graphically by fully partitioning the plane of between-firm technological spillovers and within-laboratory R\&D externalities, for all dimensions of the comparison.

We establish a number of novel results. First, positive indirect externalities are not sufficient for firms to delegate $R \& D$ to a common laboratory which needs positive benefits to participate. $R \& D$ delegation takes place if indirect externalities are not too positive (negative) when direct externalities are negative (positive). When indirect externalities are too high they counteract direct externalities and the laboratory only breaks even. Second, sufficiently high direct and indirect externalities are necessary and sufficient for optimal R\&D, firms' profits, and social welfare to be highest when firms delegate $R \& D$. Third, the laboratory participates and the delegated $R \& D$ game Pareto-dominates the other two games if (i) direct externalities are sufficiently negative (for firms to compete for the laboratory's services); and (ii) indirect externalities are positive (so that firms benefit from economies of scope) but not too high (for the laboratory to earn positive benefits). We prove that such a region always exists. Finally, our findings have a laissez-faire flavor: no regulatory intervention is required when firms decide to delegate $R \& D$ to a profit-seeking laboratory. This strong statement arises because, in this model, the privately profitable choice to contract with a laboratory also benefits consumers. Indeed, prima-facie evidence would suggest that $\mathrm{R} \& \mathrm{D}$ outsourcing is not subject to any regulation.

This paper is a first step in the analysis of procurement markets for new technology with multiple buyers. Since we use standard yet specific algebraic specifications of the cost and demand functions, future work could also test the robustness of the results to changes in the formal specifications of the 
compared games. We take a first step in that direction by using Amir (2000) to specify a modified cost function for the laboratory so as to investigate situations where R\&D is conceived as expenditures (i.e., inputs), rather than outputs. ${ }^{11}$ All our results remain valid. In another positive test of robustness, we show that our results are qualitatively similar when firms behave $\grave{a}$ la Bertrand in the product market stage of all three R\&D games. These proofs are available from the authors upon request.

Among the open questions it remains to investigate what happens when R\&D efforts lead to product innovations. This could be done by assuming that R\&D increases quality by using a framework in the spirit of Symeonidis (2003). It would be also natural to consider more than two firms. However, beyond usual tractability difficulties in computing the equilibrium, this would imply a qualitative leap in the characterization of the joint benefits function of the laboratory and any subset of firms. ${ }^{12}$ Finally, our analysis, and the whole literature on which it is based, can be criticized by its assumption of deterministic R\&D. To address that critique one may examine situations where the true cost of a $R \& D$ program is unknown before it starts. ${ }^{13}$ 


\section{Appendix}

\section{A Explicit Solutions of the Three R\&D Games}

As standard we proceed backwards. Section A.1 solves for each firm's output on the final market, which is common to three games. Then in section A.2, we solve for a firm's symmetric R\&D in each one of the three games.

\section{A.1 Final Market Stage}

Each firm chooses output to maximize its gross profits (3). This yields two reaction functions, which we use to solve for each firm's subgame Cournot-Nash equilibrium output as a function of $\mathbf{x}$ :

$$
q_{i}(\mathbf{x})=\frac{\alpha(2-\theta)+(2-\theta \beta) x_{i}-(\theta-2 \beta) x_{j}}{(2-\theta)(2+\theta) b}
$$

for $i, j=1,2, i \neq j$, and where $\alpha \equiv a-c$. Making use of (1) and (16) into (3) we obtain:

$$
\pi_{i}(\mathbf{x})=b\left[q_{i}(\mathbf{x})\right]^{2}
$$

for $i=1,2$. Now we turn to the $\mathrm{R} \& \mathrm{D}$ stage which is specific to each $\mathrm{R} \& \mathrm{D}$ game.

\section{A.2 R\&D Stage}

Define the following three terms:

$$
\begin{aligned}
& \Gamma_{1} \equiv b \gamma(2+\theta)^{2}-2(1+\beta)^{2} ; \\
& \Gamma_{2} \equiv b \gamma(2-\theta)^{2}(2+\theta)^{2}-2(2-\theta \beta)^{2} ; \\
& \Gamma_{3} \equiv b(\gamma-\delta)(2+\theta)^{2}-2(1+\beta)^{2} .
\end{aligned}
$$


In the remainder of the paper we assume that $\Gamma_{1}, \Gamma_{2}$ and $\Gamma_{3}$ are positive which guarantee that the objective function in the cooperative, non-cooperative and delegated games respectively are concave. We also define:

$$
\Gamma_{4} \equiv b \gamma(2-\theta)(2+\theta)^{2}-2(1+\beta)(2-\theta \beta)
$$

which we also assume to be positive. This will simplify the notation in what follows.

In the non-cooperative case, Henriques (1990) establishes that reaction functions in the R\&D space cross "correctly" when $\left|\partial x_{i} / \partial x_{j}\right|$ is less than 1 . Using our notational this reads as:

$$
\frac{|-2(2-\beta \theta)(2 \beta-\theta)|}{\Gamma_{2}}<1
$$

Remark that (18) for all $\beta$ when $b=\theta=1$ and $\gamma=2$, which are the values we used to draw Figures 1 to 4 .

\section{A.2.1 Cooperative $R \& D$}

The two firms' joint net profits are given by:

$$
\pi_{1}(\mathbf{x})+\pi_{2}(\mathbf{x})-\frac{\gamma}{2}\left(x_{1}^{2}+x_{2}^{2}\right)
$$

where $\pi_{1}(\mathbf{x})$ and $\pi_{2}(\mathbf{x})$ are given by (17). We maximize (19) with respect to $x_{1}$ and $x_{2}$ to obtain the symmetric cooperative R\&D outcome and individual firm profits respectively as:

$$
\begin{aligned}
& x^{\mathrm{c}}=2(1+\beta) \alpha / \Gamma_{1}, \\
& \pi^{\mathrm{c}}=\gamma \alpha^{2} / \Gamma_{1} .
\end{aligned}
$$




\section{A.2.2 Non-Cooperative $R \& D$}

Each firm chooses its R\&D independently to maximize its net profits (7). This yields two reaction functions, which we use to solve for a symmetric non-cooperative R\&D outcome:

$$
x^{\mathrm{n}}=2 \alpha(2-\theta \beta) / \Gamma_{4} .
$$

We substitute (22) into (7), and use the cost function (4), to solve for the symmetric individual firm profits:

$$
\pi^{\mathrm{n}}=\gamma \alpha^{2} \Gamma_{2} / \Gamma_{4}^{2}
$$

\section{A.2.3 Delegated R\&D}

Proposition 1 states the choice of R\&D services by the laboratory is equivalent to maximizing aggregate benefits (14) with respect to $x_{1}$ and $x_{2}$. This gives each firm's symmetric delegated R\&D outcome:

$$
x^{\mathrm{d}}=2(1+\beta) \alpha / \Gamma_{3} .
$$

Substituting (24) into (14), using the laboratory's explicit cost function (13), and simplifying gives aggregate benefits:

$$
\Lambda=2(\gamma-\delta) \alpha^{2} / \Gamma_{3}
$$

Both (24) and (25) are non-negative because by assumption $\delta \in[-\gamma, \gamma), \beta \in[0,1]$ and $\Gamma_{3}$ is positive.

\section{B Proofs of Properties 1 and 2}

To prove Property 1 we use (16) and (17) to obtain:

$$
\frac{\mathrm{d} \pi_{i}(\mathbf{x})}{\mathrm{d} x_{j}}=\frac{2(2 \beta-\theta)}{(2-\theta)(2+\theta)} q_{i}(\mathbf{x})
$$


for $i=1,2, i \neq j$. As $\theta \in[0,1]$, equation (26) is of the same sign as $(2 \beta-\theta)$ for a positive output, or equals zero otherwise.

The proof of Property 2 follows directly from differentiating (13) with respect to $x_{i}$ and $x_{j}$.

\section{Proof of Propositions}

\section{C.1 Proof of Proposition 1}

The proof of Proposition 1 is a simple adaptation in the notation from Bernheim and Whinston (1986, first part of Theorem 2 on page 14, and proof on pages 24-25). It is available upon request from the authors.

\section{C.2 Proof of Proposition 2}

Let $N=\{1,2\}$, and $2^{N}=\{\emptyset,\{1\},\{2\},\{1,2\}\}$. We build on Laussel and Le Breton (2001) - henceforth LLB - by associating to the common agency game, as defined in section 2.3 , a function $\pi: 2^{N} \rightarrow$ R, such that:

$$
\pi(M)=\max _{\mathbf{x}} \sum_{i \in M} \pi_{i}(\mathbf{x})-s(\mathbf{x})
$$

where $s(\mathbf{x})$ is given by (13) and $\pi_{i}(\mathbf{x})$ by (17). This function gives the highest joint-benefits of the laboratory and any subset $M$ of firms in $N$, with $\pi(\emptyset)=\pi_{1}(0,0)+\pi_{2}(0,0)$, that is the sum of concentrated profits with no R\&D (a normalization). Then the proof consists in investigating additive properties of $\pi$ on $2^{N}$ in order to exploit a series of theorems that characterize the equilibrium outcomes of the delegated R\&D game.

- From LLB's Theorem 3.1 (p. 102), if $\pi(M)$ is strictly subadditive, that is:

$$
\pi(\{1,2\})<\pi(\{1\})+\pi(\{2\})
$$


then the laboratory earns positive benefits in all equilibria, that is $\mathcal{L}>0$.

- From LLB's Theorem 3.3 (p. 104), if $\pi(M)$ is strictly subadditive, then $\# N=2$ implies that firms' symmetric profits in the delegated $R \& D$ game are:

$$
\pi^{\mathrm{d}}=\Lambda-\pi(\{i\})
$$

$i=1,2$.

- From LLB's Theorem 3.2 (p. 103), if $\pi(M)$ is superadditive, that is:

$$
\pi(\{1,2\}) \geq \pi(\{1\})+\pi(\{2\})
$$

then $\mathcal{L}=0$. In that case, symmetry in firms' gross profit functions, and the fact that the laboratory maximizes aggregate benefits $\Lambda(\mathbf{x})$ in (x) (Proposition 1), imply that a firm's profits in the delegated game are:

$$
\pi^{\mathrm{d}}=\Lambda / 2
$$

The remainder of the proof identifies values of $\delta$ which are such that $\pi(M)$ is either strictly subadditive or superadditive. To that effect we solve for values of $\delta$ such that (30) holds with equality, to obtain a frontier which we denote by $\delta_{\mathcal{L}=0}$. However, the free maximization of $\pi(M)$, for $M=\{i\}, i=1,2$, may yield negative maximands. Therefore, we consider in turn the free-maximum and constrainedmaximum versions of $(27)$, denoted by $\check{\pi}(\{i\})$ and $\hat{\pi}(\{i\})$, respectively. We thus obtain two frontiers $\check{\delta}_{\mathcal{L}=0}$ (free-maximum) and $\hat{\delta}_{\mathcal{L}=0}$ (constrained-maximum) each of which verify (30) with equality. We then calculate the values of $\delta$ for which the free maximand $\check{x}_{j}$ is equal to the constrained variable $\hat{x}_{j} \equiv 0$, and denote it by $\delta_{\check{x}_{j}=\hat{x}_{j}=0}$. Finally, we compare $\hat{\delta}_{\mathcal{L}=0}$ and $\check{\delta}_{\mathcal{L}=0}$ with $\delta_{\check{x}_{j}=\hat{x}_{j}=0}$ to verify for which parameter values (i) $\check{\delta}_{\mathcal{L}=0}$ verifies the positive maximand constraint, and (ii) $\hat{\delta}_{\mathcal{L}=0}$ verifies the non-positive maximand constraint. This allows us to derive the frontier $\delta_{\mathcal{L}=0}$ by "pasting" those two functions. 


\section{C.2.1 Free and Constrained Solutions}

- Firstly, we solve the free-maximum version of (27), with $M=\{i\}, i=1,2$. Define the following:

$$
\begin{aligned}
& \Gamma_{5} \equiv b\left(\gamma^{2}-\delta^{2}\right)\left(4-\theta^{2}\right)^{2}-2\left((2 \beta-\theta)^{2}+(2-\theta \beta)^{2}\right) \gamma+4(2 \beta-\theta)(2-\theta \beta) \delta \\
& \Gamma_{6} \equiv b \gamma\left(4-\theta^{2}\right)^{2}-2(\theta \beta-2)^{2} \\
& \Gamma_{7} \equiv b \gamma\left(4-\theta^{2}\right)^{2}-2(2 \beta-\theta)^{2} .
\end{aligned}
$$

We assume $\Gamma_{5}, \Gamma_{6}$, and $\Gamma_{7}$ are positive for the following free-maximum problem to be concave:

$$
\check{\pi}(\{i\})=\max _{\mathbf{x}}\left(\pi_{i}(\mathbf{x})-s(\mathbf{x})\right)
$$

where $s(\mathbf{x})$ is given by (13) and $\pi_{i}(\mathbf{x})$ by (17). Maximizing the right-hand side of (32) gives the following unconstrained R\&D solutions:

$$
\begin{aligned}
\check{x}_{i} & =2 \alpha(2-\theta)[\delta(\theta-2 \beta)+\gamma(\theta \beta-2)] / \Gamma_{5} ; \\
\check{x}_{j} & =2 \alpha(2-\theta)[\delta(\theta \beta-2)+\gamma(\theta-2 \beta)] / \Gamma_{5} .
\end{aligned}
$$

Making use of (33) and (34) into (32) we obtain, for $i=1,2$ :

$$
\check{\pi}(\{i\})=\alpha^{2}(2-\theta)^{2}\left(\delta^{2}-\gamma^{2}\right) / \Gamma_{5} .
$$

- Secondly, we solve the constrained-maximum versions of (27), with $M=\{i\}, i=1,2$. In this simpler problem, the only concavity condition imposes that $\Gamma_{6}>0$ to compute:

$$
\hat{\pi}(\{i\})=\max _{x_{i}}\left(\pi_{i}\left(x_{i}, 0\right)-r\left(x_{i}\right)\right)
$$


where $r\left(x_{i}\right)$ is given by (4), and $\pi_{i}\left(x_{i}, 0\right)$ is obtained by setting $x_{j}=\hat{x}_{j} \equiv 0$ in (17). Maximizing the right-hand side of (36) gives the constrained R\&D:

$$
\hat{x}_{i}=2(a-c)(\theta \beta-2)(\theta-2) / \Gamma_{6} .
$$

Substituting (37) into the right-hand side of (36) gives:

$$
\hat{\pi}(\{i\})=\gamma \alpha^{2}(2-\theta)^{2} / \Gamma_{7}
$$

for $i=1,2$.

- We now derive the frontier $\delta_{\check{x}_{j}=\hat{x}_{j}=0}$, i.e. all values of $\delta$ which are such that $\check{x}_{j}=\hat{x}_{j} \equiv 0$. This yields:

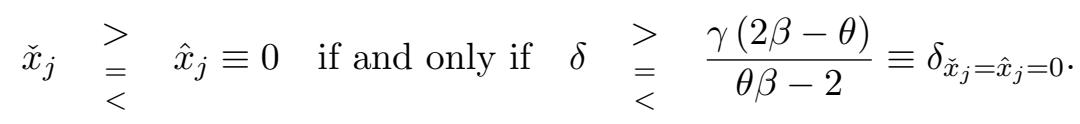

\section{C.2.2 The Laboratory's Zero-Benefits Free-maximum Frontier}

We evaluate (30), assuming it holds with equality with free-maximum profits to obtain:

$$
\pi(\{1,2\})-\check{\pi}(\{1\})-\check{\pi}(\{2\})=0
$$

where $\check{\pi}(\{1\})$ and $\check{\pi}(\{2\})$ are given by (35). There are two roots to (40). The first is $\delta=\gamma$, which however violates (32). The second root is:

$$
\delta=\frac{2 \gamma(2-\theta \beta)(\theta-2 \beta)}{(2-\theta \beta)^{2}+(2 \beta-\theta)^{2}} \equiv \check{\delta}_{\mathcal{L}=0} .
$$

To check that (41) is compatible with free maximands, recall from (39) that (41) is defined only if $\check{\delta}_{\mathcal{L}=0} \geq \delta_{\check{x}_{j}=\hat{x}_{j}=0}$. We form the difference:

$$
\delta_{\check{x}_{j}=\hat{x}_{j}=0}-\check{\delta}_{\mathcal{L}=0},
$$


and look for parameter values for which it is non-positive. Equating (42) to 0 , we find that $\beta=\theta / 2$ and $\beta=1$ are the only admissible roots (the other roots are $\gamma=0, \theta= \pm 2$, and $\beta=-1$.) Hence, (42) changes sign once in the domain of $\beta$. Evaluating (42) at some parameter values, say $(\beta, \gamma, \theta)=(0,1,1)$, we obtain $-3 / 10$. It follows that $\check{\delta}_{\mathcal{L}=0}$ is defined only for $0 \leq \beta \leq \theta / 2$.

Finally, using (41), note that the frontier $\check{\delta}_{\mathcal{L}=0}$ includes $(\beta, \delta)=(\theta / 2,0)$.

\section{C.2.3 The Laboratory's Zero-Benefits Constrained-maximum Frontier}

As in C.2.2, we evaluate (30), assuming it holds with equality but using the constrained profits (38), and solve for its roots. The first root $a=c$, is not admissible by assumption. The second root is:

$$
\delta=\frac{\gamma\left[2(2-\theta \beta)(\theta-2 \beta)-(\theta-2 \beta)^{2}\right]}{(2-\theta \beta)^{2}} \equiv \hat{\delta}_{\mathcal{L}=0}
$$

To check that the latter expression is compatible with a constrained maximand, recall from (39) that

(43) is defined only if $\hat{\delta}_{\mathcal{L}=0} \leq \delta_{\check{x}_{j}=\hat{x}_{j}=0}$. Then form the difference:

$$
\delta_{\check{x}_{j}=\hat{x}_{j}=0}-\hat{\delta}_{\mathcal{L}=0},
$$

and look for the parameter values for which it is non-negative. Equating (44) to 0 gives $\beta=\theta / 2$ as the only admissible root, and three non-admissible roots $(\gamma=0, \theta=2$, and $\beta=-1)$. Hence, (44) changes sign once over the domain of $\beta$. Evaluating (43) at some parameter values, say $(\beta, \theta, \gamma)=(0,1,1)$, gives $-1 / 4$. It follows that (44) is defined only for $\theta / 2 \leq \beta \leq 1$.

Finally, using (43), note that, as for $\check{\delta}_{\mathcal{L}=0}$, the frontier $\hat{\delta}_{\mathcal{L}=0}$ includes $(\beta, \delta)=(\theta / 2,0)$. 


\section{C.2.4 The Laboratory's Zero-Benefits Frontier}

By taking the conclusions of sections C.2.2 and C.2.3 together, we obtain that (30) holds with equality if and only if:

$$
\delta=\delta_{\mathcal{L}=0}= \begin{cases}\check{\delta}_{\mathcal{L}=0} & \text { for } \quad 0 \leq \beta \leq \theta / 2, \\ \hat{\delta}_{\mathcal{L}=0} & \text { for } \quad \theta / 2 \leq \beta \leq 1\end{cases}
$$

where $\check{\delta}_{\mathcal{L}=0}$ and $\hat{\delta}_{\mathcal{L}=0}$ are explicitly given by $(41)$ and (43). Note that $\beta=\theta / 2$ implies $\delta_{\mathcal{L}=0}=\check{\delta}_{\mathcal{L}=0}=$ $\hat{\delta}_{\mathcal{L}=0}=0$. We now prove that $\delta_{\mathcal{L}=0}$ is decreasing in $\beta$, by considering $\check{\delta}_{\mathcal{L}=0}$ and $\hat{\delta}_{\mathcal{L}=0}$ in turn.

$\left(\check{\delta}_{\mathcal{L}=0}\right)$ Differentiating (41) with respect to $\beta$ and equating to 0 yields $5 \operatorname{roots}(\gamma=0, \theta= \pm 2$, or $\beta= \pm 1)$, none of which is admissible. It follows that $\check{\delta}_{\mathcal{L}=0}$ is strictly monotone over the domain of $\beta$ on which $\check{\delta}_{\mathcal{L}=0}$ is defined, that is $[0, \theta / 2]$. To complete the proof, let for instance $\beta=\theta / 2$, and check that $\mathrm{d} \check{\delta}_{\mathcal{L}=0} / \mathrm{d} \beta<0$, as required.

$\left(\hat{\delta}_{\mathcal{L}=0}\right)$ Differentiating (43) with respect to $\beta$ and equating to 0 yields 4 roots $(\gamma=0, \theta= \pm 2$, or $\beta=-1)$, none of which is admissible. It follows that $\hat{\delta}_{\mathcal{L}=0}$ is strictly monotone over the domain of $\beta$ on which $\hat{\delta}_{\mathcal{L}=0}$ is defined, that is $[\theta / 2,1]$. To complete the proof, let, for instance $\beta=1$, and check that $\mathrm{d} \hat{\delta}_{\mathcal{L}=0} / \mathrm{d} \beta<0$, as required.

\section{C.3 Proof of Proposition 3}

Firstly, if $\beta=\theta / 2$, for all $\delta$, concentrated profits $\pi_{i}(\mathbf{x})$ depend only on each firm $i$ 's own $\mathrm{R} \& \mathrm{D}$ variable $x_{i}$ (Property 1), in which case the cooperative and non-cooperative games coincide. Secondly, if $\delta=0$, for all $\beta$, we have $r\left(x_{1}\right)+r\left(x_{2}\right)=s(\mathbf{x})$ (Property 2), and solving the cooperative game is equivalent to solving the delegated game (Proposition 1). Thirdly, if $\beta=\theta / 2$ and $\delta=0$, the laboratory earns no benefits (Proposition 2). By considering all three cases together, we conclude that the cooperative, non-cooperative, and delegated $R \& D$ games yield identical outcomes at the non-externalities point $(\theta / 2,0)$. 


\section{Proof of Lemmas}

We first establish how indirect externalities impact optimal outcomes in the delegated R\&D game. This will be useful for the proofs of Lemmas $1-3$, which follow.

Lemma D-1 (R\&D) $\mathrm{d} x^{\mathrm{d}} / \mathrm{d} \delta>0$.

Differentiating (24) with respect to $\delta$ gives:

$$
\frac{\mathrm{d} x^{\mathrm{d}}}{\mathrm{d} \delta}=2 \alpha b(1+\beta)(2+\theta)^{2} / \Gamma_{3}^{2} .
$$

The result follows from noting that the denominator of (46) is positive because of the concavity condition (18), and the numerator is also positive.

Lemma D-2 (Profits) $\mathrm{d} \pi^{\mathrm{d}} / \mathrm{d} \delta>0$.

We consider $\delta>\delta_{\mathcal{L}=0}$ and $\delta \leq \delta_{\mathcal{L}=0}$ in turn.

$\left(\delta \geq \delta_{\mathcal{L}=0}\right)$ By Propositions 1 and 2:

$$
\pi^{\mathrm{d}}=\Lambda / 2
$$

Recalling that the laboratory's cost are given by (13), aggregate benefits by (14), and using the envelope theorem, we differentiate (47) with respect to $\delta$ to obtain:

$$
\frac{\mathrm{d} \pi^{\mathrm{d}}}{\mathrm{d} \delta}=\frac{1}{2} \frac{\partial \Lambda}{\partial \delta}=\frac{1}{2}\left(x^{\mathrm{d}}\right)^{2}
$$

which is unambiguously positive given that $x^{\mathrm{d}}>0$.

$\left(\delta \leq \delta_{\mathcal{L}=0}\right)$ Assume that $\pi^{\mathrm{d}}$ is non increasing in $\delta$, that is:

$$
\left.\pi^{\mathrm{d}}\right|_{\delta<\delta_{\mathcal{L}=0}} \geq\left.\pi^{\mathrm{d}}\right|_{\delta=\delta_{\mathcal{L}=0}}
$$


and look for a contradiction. To do that, recall from Proposition 1 that the laboratory maximizes aggregate benefits, and from Proposition 2 that it exactly breaks even if $\delta=\delta_{\mathcal{L}=0}$. Consequently:

$$
\left.\pi^{\mathrm{d}}\right|_{\delta=\delta_{\mathcal{L}=0}}=\left.\frac{1}{2} \Lambda\right|_{\delta=\delta_{\mathcal{L}=0}}
$$

Moreover, recalling that the laboratory's cost are given by (13) and aggregate benefits by (14), by using the envelope theorem we obtain $\mathrm{d} \Lambda / \mathrm{d} \delta=\left(x^{\mathrm{d}}\right)^{2}$, which is unambiguously positive given that $x^{\mathrm{d}}>0$. It follows that:

$$
\left.\frac{1}{2} \Lambda\right|_{\delta=\delta_{\mathcal{L}=0}}>\left.\frac{1}{2} \Lambda\right|_{\delta<\delta_{\mathcal{L}=0}}
$$

To conclude, taking (49), (50), and (51) together leads to:

$$
\left.\pi^{\mathrm{d}}\right|_{\delta<\delta_{\mathcal{L}=0}}>\left.\frac{1}{2} \Lambda\right|_{\delta<\delta_{\mathcal{L}=0}}
$$

by transitivity. Inequality (52) contradicts the result that $\pi^{\mathrm{d}} \leq \Lambda / 2$ for all $\delta \leq \delta_{\mathcal{L}=0}$, as established by Propositions 1 and 2 . Hence $\mathrm{d} \pi^{\mathrm{d}} / \mathrm{d} \delta>0$.

Lemma D-3 (Welfare) $\mathrm{d} w^{\mathrm{d}} / \mathrm{d} \delta>0$.

Welfare is defined as the sum of firms' profits and consumer surplus. It has been established above that profits $\pi^{\mathrm{d}}$ are increasing in $\delta$. Here we turn to consumer surplus by investigating how $q_{i}\left(\mathbf{x}^{\mathrm{d}}\right)$ and $p_{i}\left(\mathbf{x}^{\mathrm{d}}\right)$ vary with $\delta$.

$\left(q_{i}\left(\mathbf{x}^{\mathrm{d}}\right)\right)$ Differentiating the Cournot-Nash symmetric equilibrium output (16) evaluated at $\mathbf{x}^{\mathrm{d}}=\left(x^{\mathrm{d}}, x^{\mathrm{d}}\right)$, with respect to $\delta$, we obtain:

$$
\frac{\mathrm{d} q_{i}\left(\mathbf{x}^{\mathrm{d}}\right)}{\mathrm{d} \delta}=\frac{(2+\theta)(1+\beta) x^{\mathrm{d}}}{\Gamma_{3}}
$$

As the denominator of (53) is positive because of (18), and all other parameters of the model as well as $x^{\mathrm{d}}$ are positive, it follows that (53) is also positive. 
$\left(p_{i}\left(\mathbf{x}^{\mathrm{d}}\right)\right)$ Differentiating the inverse demand function (1) evaluated at the symmetric equilibrium $\mathbf{x}^{\mathrm{d}}=$ $\left(x^{\mathrm{d}}, x^{\mathrm{d}}\right)$, with respect to $\delta$, we obtain:

$$
\frac{\mathrm{d} p_{i}\left(\mathbf{x}^{\mathrm{d}}\right)}{\mathrm{d} \delta}=-\frac{b(1+\theta)(2+\theta)(1+\beta) x^{\mathrm{d}}}{\Gamma_{3}}
$$

As the denominator of (54) is positive because of (18), it follows that (54) is negative.

Taking (53) and (54) together means that the consumer surplus is increasing in $\delta$. The fact that firms' profits are also increasing in $\delta$ (Lemma D-2) completes the proof.

\section{D.1 Proof of Lemma 1}

\section{D.1.1 Equal Delegated and Cooperative R\&D Frontier $\delta_{x^{\mathrm{d}}=x^{\mathrm{c}}}$}

As $x^{\mathrm{d}}$ is monotone increasing in $\delta$ (Lemma D-1) and $x^{\mathrm{c}}$ is invariant with $\delta$, it follows that if there exists a value of $\delta$ for which $x^{\mathrm{d}}=x^{\mathrm{c}}$, it is unique. Moreover, for $\delta=0$, (i) the costs of R\&D are the same for the laboratory in the delegated $R \& D$ and for both firms in the cooperative game (see Property 2), and (ii) solving the delegated game for $x^{\mathrm{d}}$ is equivalent to solving the cooperative game for $x^{\mathrm{c}}$ (because of Proposition 1). Hence, $x^{\mathrm{d}}=x^{\mathrm{c}}$ for $\delta=0$. Making use of that result, Lemma D-1, that $x^{\mathrm{c}}$ does not vary with $\delta$ and Proposition 2 gives Lemma 1- $(i)$.

\section{D.1.2 Equal Delegated and Non-Cooperative R\&D Frontier $\delta_{x^{\mathrm{d}}=x^{\mathrm{n}}}$}

Using (22) and (24) we define:

$$
\Delta(\delta) \equiv x^{\mathrm{d}}-x^{\mathrm{n}}
$$

$$
(\beta=\theta / 2)
$$

Proposition 3 establishes that $\Delta(0)=0$.

$$
(\beta<\theta / 2)
$$


Claim A: $\Delta(\delta)<0$. Section D.1.1 establishes that $x^{\mathrm{d}}=x^{\mathrm{c}}$ for $\delta=0$. Next, we know from d'Aspremont and Jacquemin (1988) that $x^{\mathrm{c}}<x^{\mathrm{n}}$ for $\beta \in[0, \theta / 2)$ and all values of $\delta$. Claim A follows by transitivity.

Claim B: $\Delta(\delta)>0$ along $\delta_{\mathcal{L}=0}$. Recall from (45) that $\delta_{\mathcal{L}=0}=\check{\delta}_{\mathcal{L}=0}>0$ for $\beta<\theta / 2$. Then evaluating (55) at $\delta=\check{\delta}_{\mathcal{L}=0}$, and equating to 0 gives $7 \operatorname{roots}(\gamma=0, \theta= \pm 2, \alpha=0, \beta=\theta / 2, \beta=$ $1, b=0$. $)$, none of which is admissible. Therefore, $\Delta\left(\check{\delta}_{\mathcal{L}=0}\right)$ does not change sign over this range of $\beta$. It is straightforward to check that claim B holds by computing $\Delta\left(\check{\delta}_{\mathcal{L}=0}\right)$ at, say, $\beta=0$ and any admissible values for the other parameters, and obtaining a positive value.

$(\beta>\theta / 2)$

Claim C: $\Delta(\delta)>0$ for $\delta=0$. Recall that $x^{\mathrm{d}}=x^{\mathrm{c}}$ for $\delta=0$, as established in Section D.1.1. Then note that $x^{\mathrm{c}}>x^{\mathrm{n}}$ for $\beta \in(\theta / 2,1]$ from d'Aspremont and Jacquemin (1988), all $\delta$. Claim C follows by transitivity.

Claim D: $\Delta(\delta)<0$ along $\delta_{\mathcal{L}=0}$. Recall from (45) that $\delta_{\mathcal{L}=0}=\hat{\delta}_{\mathcal{L}=0}<0$ for $\beta>\theta / 2$, evaluate $(55)$ at $\delta=\hat{\delta}_{\mathcal{L}=0}$, and equating to 0 gives $7 \operatorname{roots}(\gamma=0, \theta= \pm 2, \alpha=0, \beta=\theta / 2, \beta=2 / \theta, b=0$.), none of which is admissible. Therefore, $\Delta\left(\hat{\delta}_{\mathcal{L}=0}\right)$ does not change sign over the relevant range of $\beta$. It is straightforward to check that $\Delta\left(\hat{\delta}_{\mathcal{L}=0}\right)$ is negative by evaluating it at, say, $\beta=1$ and any value for other parameters. Hence claim D is true.

Recall how $\delta_{\mathcal{L}=0}$ is constructed in (45). Using claims $\mathrm{A}$ to $\mathrm{D}$, that $x^{\mathrm{d}}$ is continuous and monotone increasing in $\delta$ (Lemma D-1) while $x^{\mathrm{n}}$ does not vary with $\delta$, means there exists a unique $\delta \equiv \delta_{x^{\mathrm{d}}=x^{\mathrm{n}}}$ such that $x^{\mathrm{d}} \underset{\gtrless}{\gtrless} x^{\mathrm{n}}$ if and only if $\delta \stackrel{\gtrless}{\gtrless} \delta_{x^{\mathrm{d}}=x^{\mathrm{n}}}$, with $\delta_{x^{\mathrm{d}}=x^{\mathrm{n}}}$ as in Lemma 1- $(i i)$.

\section{D.2 Proof of Lemma 2}

\section{D.2.1 Equal Delegated and Cooperative Profits Frontier $\delta_{\pi^{\mathrm{d}}=\pi^{\mathrm{c}}}$}

$$
(\beta=\theta / 2)
$$


We know from Proposition 3 that $\pi^{\mathrm{d}}=\pi^{\mathrm{c}}$ for $\delta=0$ (the no-externalities case).

Now we consider $\beta<\theta / 2$, for which $\delta_{\mathcal{L}=0}>0$, and $\beta>\theta / 2$, for which $\delta_{\mathcal{L}=0}<0$.

$(\beta<\theta / 2)$

Claim A: $\pi^{\mathrm{d}}<\pi^{\mathrm{c}}$ for $\delta=0$. On the one hand:

$$
\pi^{\mathrm{d}}<\left.\frac{1}{2} \Lambda\right|_{\delta=0}
$$

because the laboratory appropriates a share of maximized aggregate benefits as $\mathcal{L}>0$ for $\delta=$ $0<\delta_{\mathcal{L}=0}$, as can be inferred from Propositions 1 and 2 . On the other hand:

$$
\pi^{\mathrm{c}}=\left.\frac{1}{2} \Lambda\right|_{\delta=0}
$$

from the specification of the cooperative R\&D game. Putting (56) and (57) together gives $\pi^{\mathrm{d}}<\pi^{\mathrm{c}}$ for $\delta=0$.

Claim B: $\pi^{\mathrm{d}}>\pi^{\mathrm{c}}$ for $\delta=\delta_{\mathcal{L}=0}$. On the one hand:

$$
\pi^{\mathrm{d}}=\left.\frac{1}{2} \Lambda\right|_{\delta=\delta_{\mathcal{L}=0}}
$$

from Propositions 1 and 2 because firms earn all maximized aggregate benefits as $\mathcal{L}=0$ for $\delta=\delta_{\mathcal{L}=0}$. On the other hand:

$$
\pi^{\mathrm{c}}<\left.\frac{1}{2} \Lambda\right|_{\delta=\delta_{\mathcal{L}=0}}
$$

because of (57) and $\left.\Lambda\right|_{\delta=0}<\left.\Lambda\right|_{\delta=\delta_{\mathcal{L}=0}}$ as a result of (48). Putting (58) and (59) together means claim B holds.

$(\beta>\theta / 2)$

Claim C: $\pi^{\mathrm{d}}=\pi^{\mathrm{c}}$ for $\delta=0$. On the one hand:

$$
\pi^{\mathrm{d}}=\left.\frac{1}{2} \Lambda\right|_{\delta=0}
$$


from Propositions 1 and 2 (as $\mathcal{L}=0$ for $\delta=0>\delta_{\mathcal{L}=0}$ ). On the other hand,

$$
\pi^{\mathrm{c}}=\left.\frac{1}{2} \Lambda\right|_{\delta=0},
$$

from the specification of the cooperative R\&D game. Claim C follows from (60) and (61).

Claim D: $\delta_{\mathcal{L}=0}<0$ for $\beta>\theta / 2$. That claim follows directly from Proposition 2 .

Given claims A to D, that $\pi^{\mathrm{d}}$ is continuous and monotone increasing in $\delta$ (Lemma D-2) means there exists a unique $\delta \equiv \delta_{\pi^{\mathrm{d}}=\pi^{\mathrm{c}}}$ such that $\pi^{\mathrm{d}} \gtreqless \pi^{\mathrm{c}}$ if and only if $\delta \geqq \delta_{\pi^{\mathrm{d}}=\pi^{\mathrm{c}}}$, with $\delta_{\pi^{\mathrm{d}}=\pi^{\mathrm{c}}}$ as in Lemma $2-(i)$.

\section{D.2.2 Equal Delegated and Non-Cooperative Profits Frontier $\delta_{\pi^{\mathrm{d}}=\pi^{\mathrm{n}}}$}

$(\beta=\theta / 2)$

We know from Proposition 3 that $\pi^{\mathrm{d}}=\pi^{\mathrm{n}}$ for $\delta=0$.

Now we consider $\beta<\theta / 2$, for which $\delta_{\mathcal{L}=0}>0$, and $\beta>\theta / 2$, for which $\delta_{\mathcal{L}=0}<0$. In both cases, we make use of $\delta_{x^{\mathrm{d}}=x^{\mathrm{n}}}$ as defined in Lemma 1. Note that $\delta_{x^{\mathrm{d}}=x^{\mathrm{n}}}$ is identical to $\delta_{\check{x}_{j}=\hat{x}_{j}=0}$, for all $\beta$. Indeed, the unique admissible root to $x^{\mathrm{d}}-x^{\mathrm{n}}=0$ is:

$$
\delta=\frac{\gamma(\theta-2 \beta)}{(2-\theta \beta)}
$$

which is the same as (39). The other non-admissible roots to $x^{\mathrm{d}}-x^{\mathrm{n}}=0$ are $\alpha=0, \theta=-2$, and $b=0$.

$$
(\beta<\theta / 2)
$$

Claim A: $\pi^{\mathrm{d}}<\pi^{\mathrm{n}}$ for $\delta=\delta_{x^{\mathrm{d}}=x^{\mathrm{n}}}$. To prove claim A note that as $\delta=\delta_{\check{x}_{j}=\hat{x}_{j}=0}=\delta_{x^{\mathrm{d}}=x^{\mathrm{n}}}$, it follows that $\pi^{\mathrm{d}}=\Lambda-\pi(\{i\})$ from Proposition $2,{ }^{14}$ with $\pi(\{i\})=\check{\pi}(\{i\})=\hat{\pi}(\{i\})$ because of the definition of $\delta_{\check{x}_{j}=\hat{x}_{j}=0}$. Using the latter and (23) we define:

$$
\tilde{\Delta}(\delta)=\pi^{\mathrm{d}}-\pi^{\mathrm{n}}
$$


As the roots to $\tilde{\Delta}\left(\delta_{x^{\mathrm{d}}=x^{\mathrm{n}}}\right)=0(\gamma=0, \alpha=0, \beta=\theta / 2, \beta=2 / \theta)$ are not admissible, $\tilde{\Delta}\left(\delta_{x^{\mathrm{d}}=x^{\mathrm{n}}}\right)$ does not change sign. It suffices to evaluate (62) at, say, $\beta=0$, to check that claim A is valid. Claim B: $\pi^{\mathrm{d}}>\pi^{\mathrm{n}}$ for $\delta=\delta_{\pi^{\mathrm{d}}=\pi^{\mathrm{c}}}$. We know that $\pi^{\mathrm{d}}=\pi^{\mathrm{c}}$ along $\delta_{\pi^{\mathrm{d}}=\pi^{\mathrm{c}}}$ by definition, while $\pi^{\mathrm{c}}>\pi^{\mathrm{n}}$ for $\beta<\theta / 2$ and any $\delta$ from d'Aspremont and Jacquemin (1988). Therefore, by transitivity claim $\mathrm{B}$ is true.

$(\beta>\theta / 2)$

Claim C: $\pi^{\mathrm{d}}<\pi^{\mathrm{n}}$ for $\delta=\delta_{x^{\mathrm{d}}=x^{\mathrm{n}}}$. Recall from (2) that the unit costs of production are equal under delegated and non-cooperative R\&D along $\delta_{x^{\mathrm{d}}=x^{\mathrm{n}}}$. Thus, from (1) and (16), $q_{i}\left(\mathbf{x}^{\mathrm{d}}\right)=q_{i}\left(\mathbf{x}^{\mathrm{n}}\right)$ and $p_{i}\left(\mathbf{x}^{\mathrm{d}}\right)=p_{i}\left(\mathbf{x}^{\mathrm{n}}\right)$, for $i=1,2$, along $\delta_{x^{\mathrm{d}}=x^{\mathrm{n}}}$. It follows that gross concentrated profits (i.e., before $R \& D$ costs) are also equal, that is:

$$
\pi_{i}\left(\mathbf{x}^{\mathrm{d}}\right)=\pi_{i}\left(\mathbf{x}^{\mathrm{n}}\right)
$$

$i=1,2$. Moreover, we know from Lemma 1-(ii) that $\delta_{\mathcal{L}=0}<\delta_{x^{\mathrm{d}}=x^{\mathrm{n}}}<0$. The first inequality sign means that the laboratory exactly breaks even along $\delta_{x^{\mathrm{d}}=x^{\mathrm{n}}}$ because of Proposition 2. This implies that firms' symmetric transfer payments exactly cover the laboratory's costs, that is $t_{1}^{\mathrm{d}}\left(\mathbf{x}^{\mathrm{d}}\right)+t_{2}^{\mathrm{d}}\left(\mathbf{x}^{\mathrm{d}}\right)=s\left(\mathbf{x}^{\mathrm{d}}\right)$. The second inequality means indirect externalities are negative along $\delta_{x^{\mathrm{d}}=x^{\mathrm{n}}}$, because of Property 2. This implies that the laboratory's R\&D costs are strictly greater than the firms' total R\&D costs, that is $s\left(\mathbf{x}^{\mathrm{d}}\right)>r\left(x_{1}^{\mathrm{n}}\right)+r\left(x_{2}^{\mathrm{n}}\right)$, with $x_{1}^{\mathrm{n}}=x_{2}^{\mathrm{n}}=x^{\mathrm{n}}$. It follows that $t_{i}^{\mathrm{d}}\left(\mathbf{x}^{\mathrm{d}}\right)>r\left(x_{i}^{\mathrm{n}}\right)$ along $\delta_{x^{\mathrm{d}}=x^{\mathrm{n}}}$. It suffices to use (63) to obtain:

$$
\pi_{i}\left(\mathbf{x}^{\mathrm{d}}\right)-t_{i}^{\mathrm{d}}\left(\mathbf{x}^{\mathrm{d}}\right)<\pi_{i}\left(\mathbf{x}^{\mathrm{n}}\right)-r\left(x_{i}^{\mathrm{n}}\right),
$$

$i=1,2$. Inequality (64) says that claim $\mathrm{C}$, which refers to net profits, is true.

Claim D: $\pi^{\mathrm{d}}>\pi^{\mathrm{n}}$ for $\delta=0$. In the absence of indirect externalities, we have $s(\mathbf{x})=r\left(x_{1}\right)+r\left(x_{2}\right)$. In that case, from Proposition 1, we know that solving the delegated game for $\mathrm{x}^{\mathrm{d}}$ is equivalent to solving the cooperative game for $\mathbf{x}^{\mathrm{c}}$. Then, from Proposition 2, because $\delta=0>\delta_{\mathcal{L}=0}$ implies 
that the laboratory exactly breaks even, we have $\pi^{\mathrm{d}}=\pi^{\mathrm{c}}$. As $\pi^{\mathrm{c}}$ is always greater than $\pi^{\mathrm{n}}$, from d'Aspremont and Jacquemin (1988), claim D follows by transitivity.

Given claims A to D, that $\pi^{\mathrm{d}}$ is continuous and monotone increasing in $\delta$ from Lemma D-2, and $\pi^{\mathrm{n}}$ is invariant with $\delta$, means there exists a unique $\delta \equiv \delta_{\pi^{\mathrm{d}}=\pi^{\mathrm{n}}}$ such that $\pi^{\mathrm{d}} \underset{<}{\gtrless} \pi^{\mathrm{n}}$ if and only if $\delta \underset{\pi^{\mathrm{d}}=\pi^{\mathrm{n}}}{ }$, with $\delta_{\pi^{\mathrm{d}}=\pi^{\mathrm{n}}}$ as in Lemma $2-(i i)$.

\section{D.3 Proof of Lemma 3}

\section{D.3.1 Equal Delegated and Cooperative Welfare Frontier $\delta_{w^{\mathrm{d}}=w^{\mathrm{c}}}$}

As $w^{\mathrm{d}}$ is monotone increasing in $\delta$ (Lemma D-3), and $w^{\mathrm{c}}$ does not vary with $\delta$, it follows that if there exists a value of $\delta$ such that $w^{\mathrm{d}}=w^{\mathrm{c}}$, it is unique. Moreover, for $\delta=0$, we know (i) the laboratory's costs in the delegated game are equal to both firms' total R\&D costs in the cooperative game (Property 2), and (ii) solving the delegated game for $x^{\mathrm{d}}$ is equivalent to solving the delegated game for $x^{\mathrm{c}}$ (Proposition 1). Hence, the two games yield the same equilibrium quantities and prices, that is $q_{i}\left(\mathbf{x}^{\mathrm{d}}\right)=q_{i}\left(\mathbf{x}^{\mathrm{c}}\right)$ and $p_{i}\left(\mathbf{x}^{\mathrm{d}}\right)=p_{i}\left(\mathbf{x}^{\mathrm{c}}\right), i=1,2$. Recalling that $w^{\mathrm{d}}$ is continuous and monotone increasing in $\delta$, whereas $w^{\mathrm{c}}$ is invariant with $\delta$, gives Lemma $3-(i)$.

\section{D.3.2 Equal Delegated and Non-Cooperative Welfare Frontier $\delta_{w^{\mathrm{d}}=w^{\mathrm{n}}}$}

$(\beta=\theta / 2)$

We know from Proposition 3 that $w^{\mathrm{d}}=w^{\mathrm{n}}$ for $\delta=0$.

Now we turn to other the values of $\beta$.

i) We compare consumer surpluses and gross concentrated profits (i.e., before R\&D costs), in the delegated and non-cooperative games along $\delta_{x^{\mathrm{d}}=x^{\mathrm{n}}}$, and show they are the same. To see that, recall that $x^{\mathrm{d}}=x^{\mathrm{n}}$ along $\delta_{x^{\mathrm{d}}=x^{\mathrm{n}}}$, by definition. Therefore production costs, together with quantities 
and thus prices, are identical in the two games, that is $c_{i}\left(\mathbf{x}^{\mathrm{d}}\right)=c_{i}\left(\mathbf{x}^{\mathrm{n}}\right), q_{i}\left(\mathbf{x}^{\mathrm{d}}\right)=q_{i}\left(\mathbf{x}^{\mathrm{n}}\right)$, and $p_{i}\left(\mathbf{x}^{\mathrm{d}}\right)=p_{i}\left(\mathbf{x}^{\mathrm{n}}\right), i=1,2$. It follows that firms' gross profits and consumer surpluses are the same in the delegated and non-cooperative $\mathrm{R} \& \mathrm{D}$ games along $\delta_{x^{\mathrm{d}}=x^{\mathrm{n}}}$.

ii) We show that the sign of the difference between total R\&D costs in the delegated and noncooperative games along $\delta_{x^{\mathrm{d}}=x^{\mathrm{n}}}$ depends on the sign of direct externalities. To see that, observe that $-\delta x_{1} x_{2} \lesseqgtr 0$ if and only if $\delta \geqq 0$, for all $x_{1}, x_{2}>0$. Then recall from Lemma $1-(i i)$ that $\delta_{x^{\mathrm{d}}=x^{\mathrm{n}}} \geqq 0$ if and only if $\beta \leqq \theta / 2$. It follows that:

$$
-\delta_{x^{\mathrm{d}}=x^{\mathrm{n}}} x_{1} x_{2} \underset{+}{>} 0 \text { if and only if } \begin{array}{r}
> \\
\stackrel{>}{>}
\end{array}
$$

for all $x_{1}, x_{2}>0$. Hence, (65) means that along $\delta_{x^{\mathrm{d}}=x^{\mathrm{n}}}$, the laboratory's costs are less than (equal to, greater than) firms' total in-house $R \& D$ costs if and only if $\beta$ is less than (equal to, greater than) $\theta / 2$.

As welfare is the sum of consumer surplus and firms' net profits, it follows from i) and ii) that:

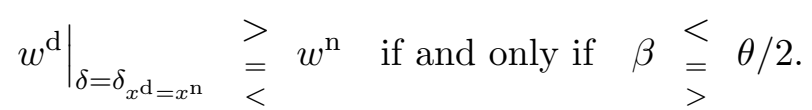

We now use (66) to establish the existence of $\delta_{w^{\mathrm{d}}=w^{\mathrm{n}}}$ for $\beta<\theta / 2$, and $\beta>\theta / 2$ respectively.

$(\beta<\theta / 2)$

Claim A: $w^{\mathrm{d}}>w^{\mathrm{n}}$ along $\delta_{x^{\mathrm{d}}=x^{\mathrm{n}}}$. This claim follows from (66). Moreover $\delta_{x^{\mathrm{d}}=x^{\mathrm{n}}}<\delta_{\pi^{\mathrm{d}}=\pi^{\mathrm{n}}}$ from Lemma 2-(ii), for $\beta<\theta / 2$.

Claim B: $w^{\mathrm{d}}<w^{\mathrm{n}}$ for $\delta=0$. Recall that $w^{\mathrm{c}}=w^{\mathrm{d}}$ for $\delta=0$ by Proposition 1 , and $w^{\mathrm{c}}<w^{\mathrm{n}}$ for $\beta<\theta / 2$ from d'Aspremont and Jacquemin (1988). Claim B follows by transitivity.

$$
(\beta>\theta / 2)
$$

Claim C: $w^{\mathrm{d}}<w^{\mathrm{n}}$ along $\delta_{x^{\mathrm{d}}=x^{\mathrm{n}}}$, for $\beta>\theta / 2$. The proof of claim C follows directly from (66). 
Claim D: $w^{\mathrm{d}}>w^{\mathrm{n}}$ for $\delta=\delta_{\pi^{\mathrm{d}}=\pi^{\mathrm{n}}}$. On the firms' side, $\pi^{\mathrm{d}}=\pi^{\mathrm{n}}$ on $\delta_{\pi^{\mathrm{d}}=\pi^{\mathrm{n}}}$ by definition. On the consumers' side, because $\delta_{\pi^{\mathrm{d}}=\pi^{\mathrm{n}}}>\delta_{x^{\mathrm{d}}=x^{\mathrm{n}}}$ from Lemma 2- $(i i)$, we obtain $x^{\mathrm{d}}>x^{\mathrm{n}}$, and consequently $c_{i}\left(\mathbf{x}^{\mathrm{d}}\right)<c_{i}\left(\mathbf{x}^{\mathrm{n}}\right)$ leads to $q_{i}\left(\mathbf{x}^{\mathrm{d}}\right)>q_{i}\left(\mathbf{x}^{\mathrm{n}}\right)$ and $p_{i}\left(\mathbf{x}^{\mathrm{d}}\right)<p_{i}\left(\mathbf{x}^{\mathrm{n}}\right), i=1,2$, on $\delta_{\pi^{\mathrm{d}}=\pi^{\mathrm{n}}}$. On the laboratory's side, we know that $\delta_{\pi^{\mathrm{d}}=\pi^{\mathrm{n}}}>\delta_{\mathcal{L}=0}$ from Lemma 2 - $(i i)$ in the case of positive direct externalities, which implies that $\mathcal{L}=0$ from Proposition 2. As firms and consumers are better-off in the delegated R\&D game than in the non-cooperative one, while the laboratory earns zero benefits in either game, means that claim $\mathrm{D}$ is true.

Using claims $\mathrm{A}$ to $\mathrm{D}$, that $w^{\mathrm{d}}$ is continuous and monotone increasing in $\delta$ (Lemma D-3), while $w^{\mathrm{n}}$ does not vary with $\delta$, means there exists a unique $\delta \equiv \delta_{w^{\mathrm{d}}=w^{\mathrm{n}}}$ such that $w^{\mathrm{d}} \geqq w^{\mathrm{n}}$ if and only if $\delta \geqq \delta_{w^{\mathrm{d}}=w^{\mathrm{n}}}$, with $\delta_{w^{\mathrm{d}}=w^{\mathrm{n}}}$ as in Lemma 3- $(i i)$. 


\section{E Figures}

All four figures are drawn for $a=1, b=1, c=3 / 4, \gamma=2, \theta=1$. Figures $1,2,3$ include a reference to the following results by d'Aspremont and Jacquemin (1988): $(i)$ $x^{\mathrm{c}} \geqq x^{\mathrm{n}}$ if and only if $\beta \geqq \theta / 2 ;(i i) \pi^{\mathrm{c}}=\pi^{\mathrm{n}}$ at $\beta=\theta / 2$, otherwise $\pi^{\mathrm{c}}>\pi^{\mathrm{n}} ;$ and $(i i i)$ $w^{\mathrm{c}} \underset{<}{\gtrless} w^{\mathrm{n}}$ if and only if $\beta \underset{<}{\geqq} \theta / 2$.

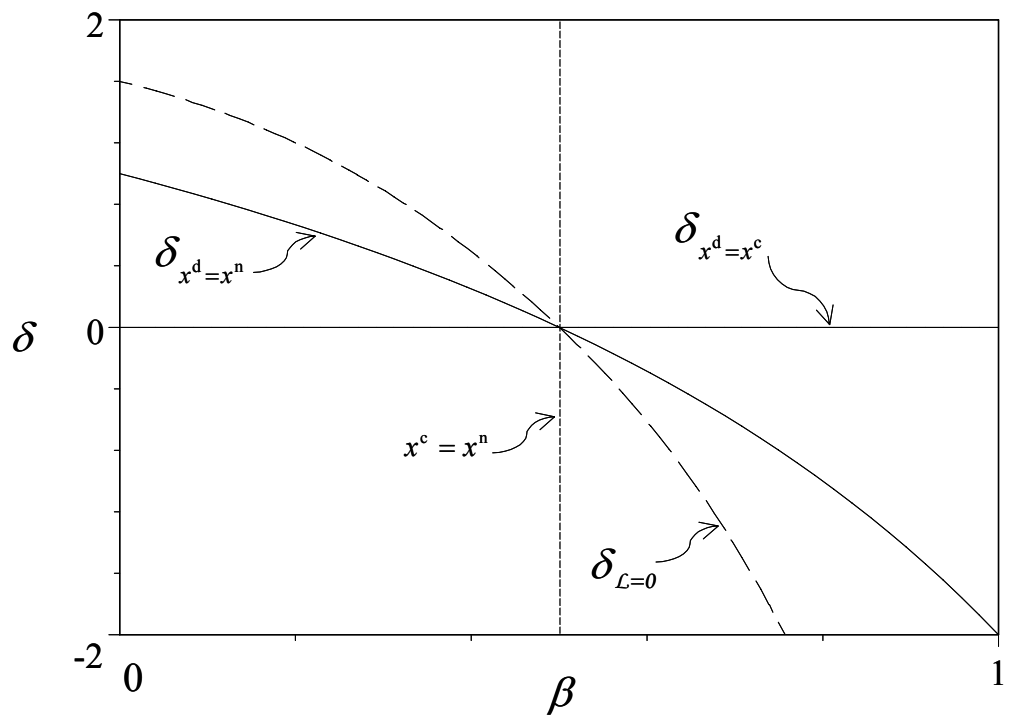

Figure 1: (R\&D outcomes): $x^{\mathrm{d}} \underset{<}{\gtrless} x^{\mathrm{n}}$ if and only if $\delta \geqq \delta_{x^{\mathrm{d}}=x^{\mathrm{n}}}$, and $x^{\mathrm{d}} \underset{<}{\gtrless} x^{\mathrm{c}}$ if and only if $\delta \underset{<}{\gtrless} \delta_{x^{\mathrm{d}}=x^{\mathrm{c}}}=0$. 


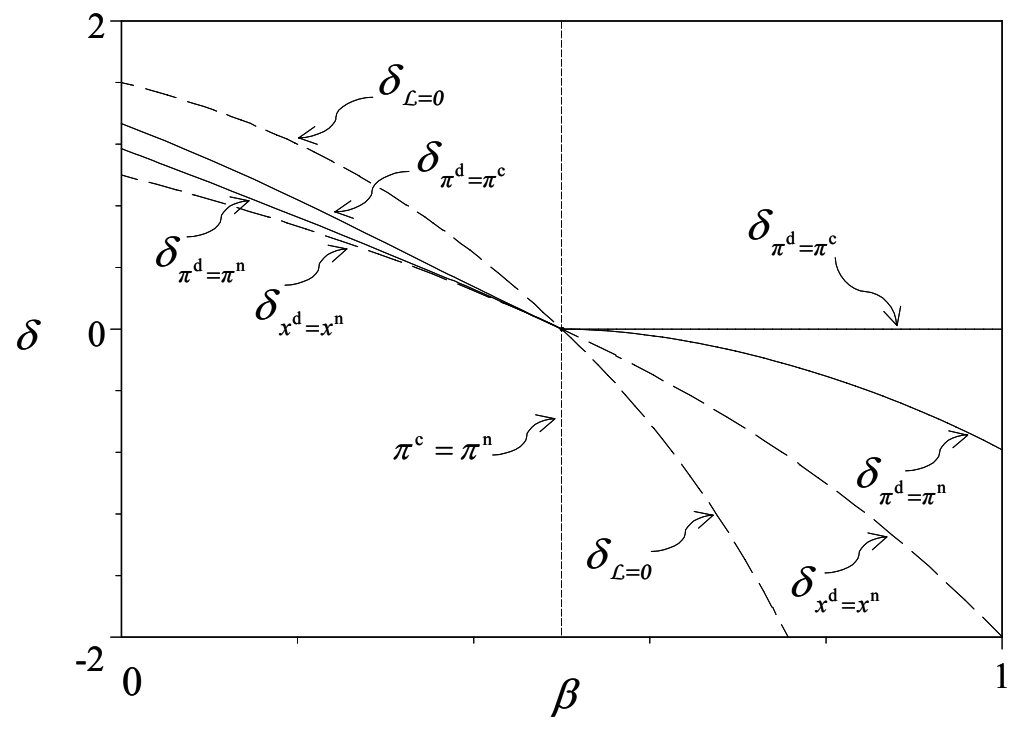

Figure 2: (Firms' profits): $\pi^{\mathrm{d}} \underset{<}{\gtrless} \pi^{\mathrm{n}}$ if and only if $\delta \underset{<}{\gtrless} \delta_{\pi^{\mathrm{d}}=\pi^{\mathrm{n}}}$, and $\pi^{\mathrm{d}} \underset{<}{\gtrless} \pi^{\mathrm{c}}$ if and only if $\delta \underset{<}{\gtrless} \delta_{\pi^{\mathrm{d}}=\pi^{\mathrm{c}}}$. 


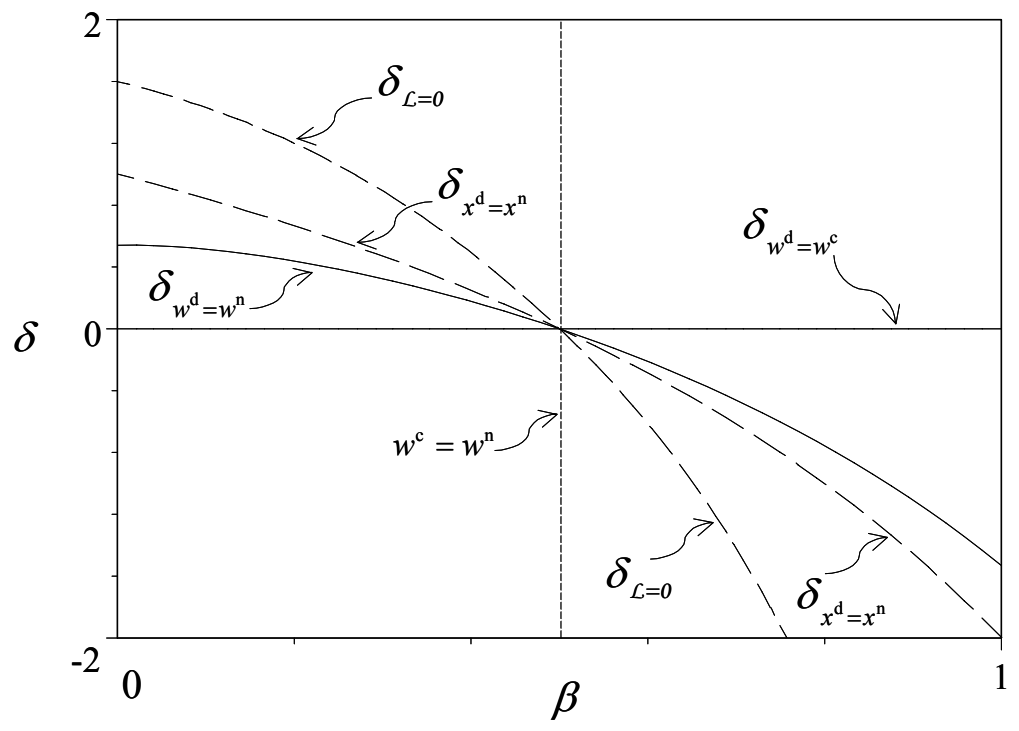

Figure 3: (Social welfare): $w^{\mathrm{d}} \gtreqless \underset{k}{\gtrless} w^{\mathrm{n}}$ if and only if $\delta \underset{<}{\gtrless} \delta_{w^{\mathrm{d}}=w^{\mathrm{n}}}$, and $w^{\mathrm{d}} \gtreqless \underset{<}{\gtrless} w^{\mathrm{c}}$ if and only if $\delta \underset{<}{\gtrless} \delta_{w^{\mathrm{d}}=w^{\mathrm{c}}}$. 


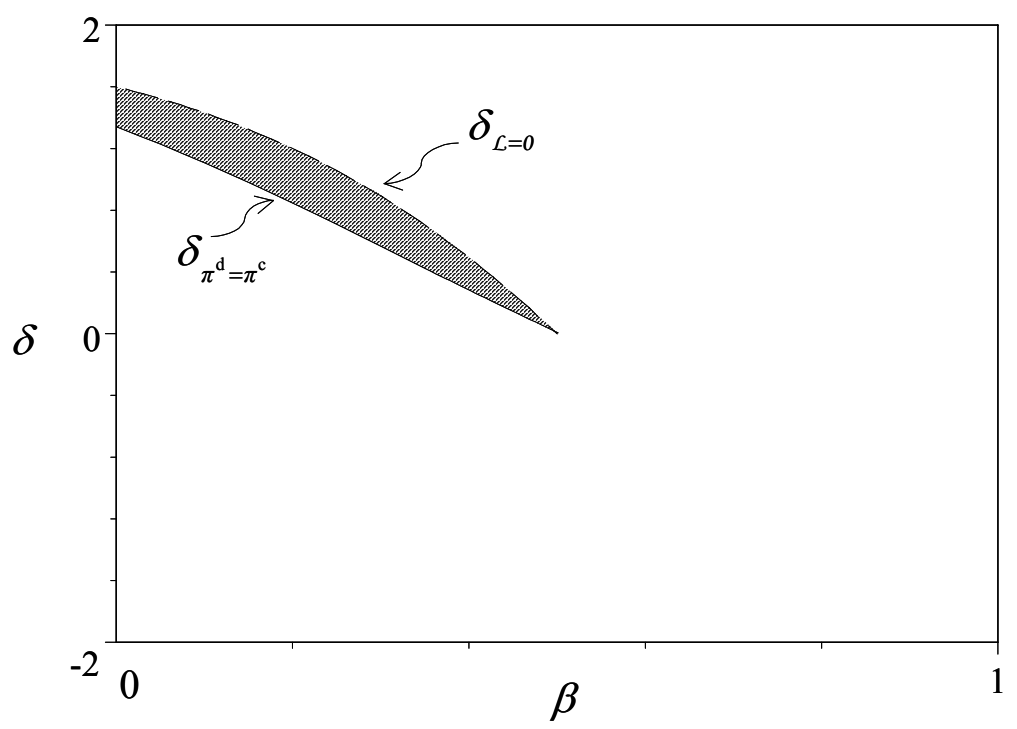

Figure 4: (Delegation dominance): the shaded area represents the set of points $(\beta, \delta)$ for which the delegated R\&D game is a Pareto optimal organizational form of R\&D, and the laboratory earns positive benefits. 


\section{Notes}

${ }^{1}$ These numbers refer to industrial R\&D performed outside a company's facilities and funded from all sources except the Federal Government. For details and distributions by industry and by size of company, see NSF (2003, Table A-10, pp. 46-47).

${ }^{2}$ Dobler and Burt (1996) observe that "R\&D services normally are purchased through one of the two methods of compensation: a fixed price for a level of effort (e.g., fifty days) or a cost plus fixed or award fee" (p. 416).

${ }^{3}$ For details on these contracts, and other examples, see: www.recap.com/bday.nsf.

${ }^{4}$ For example, Kamien, Tauman and Zang (1988) examine the case of a superior product which is licensed to producers of an inferior substitute through a fixed fee. Kamien, Oren and Tauman (1992b) compare alternative licensing strategies, namely a fixed fee, a per unit royalty, and the auctioning of a fixed number of licenses.

${ }^{5}$ For instance, Kamien, Muller and Zang (1992a) consider spillovers on the input side of the R\&D stage, Suzumura (1992) introduces a second-best welfare criterion, Motta (1992) and Rosenkranz (1995) consider quality-improving R\&D, Vonortas (1994) distinguishes between generic research and commercial development, Poyago-Theotoky (1999) and Kamien and Zang (2000) endogeneize spillovers, and Hinloopen (2000) introduces Bertrand competition on the final market with more than two firms.

${ }^{6}$ See Martin (2001) for a critical overview of that literature.

${ }^{7}$ The business literature (Howells, James and Malik 2003, for example) opposes the outsourcing of new technological knowledge, under conditions stipulated in a contract agreed beforehand, to firms licensing existing technological knowledge.

${ }^{8}$ This terminology is similar to what Laffont and Martimort (1997) call "type 1" (indirect) and "type 2" (direct) externalities.

${ }^{9}$ Aghion and Tirole (1994) and Ambec and Poitevin (2001) differ fundamentally in their theoretical use of the nondeterministic R\&D assumption. While Aghion and Tirole (1994) emphasize the non-contractibility of the uncertain R\&D outcome, Ambec and Poitevin (2001) stress an informational problem as attached to the risky nature of R\&D tasks.

${ }^{10}$ The proofs of the existence and stability properties, that characterize truthful Nash equilibria for a class of common agency games which include the present specification, are in Bernheim and Whinston (1986). 
${ }^{11}$ More formally, $r\left(x_{i}\right)=\frac{\gamma}{2}(1+\beta) x_{i}^{2}$, in the cooperative and non-cooperative in-house R\&D games. In this case, Amir (2000) demonstrates that d'Aspremont and Jacquemin (1988), in which $\mathbf{x}$ is a vector of R\&D outcomes, and Kamien et al. (1992a), in which $\mathbf{x}$ describes R\&D investments, yield the same effective cost-reducing outcomes. We let the laboratory's cost function be $s(\mathbf{x})=\frac{\gamma}{2}(1+\beta)\left(x_{1}^{2}+x_{2}^{2}\right)-\delta x_{1} x_{2}$.

${ }^{12} \mathrm{~A}$ first step towards the generalization of the delegated R\&D model to more than two firms is easily obtained by applying two recent results by Billete de Villemeur and Versaevel (2003). They establish sufficient conditions for $\pi(M)$, as defined in (27), with $M \in 2^{N}$ and $\# N \geq 2$, to be either strictly subadditive or convex (and thus for the laboratory to earn positive benefits or to exactly break even, respectively). However, $\pi(M)$ should be strongly subbadditive to obtain $\pi^{\mathrm{d}}=\Lambda-\pi(N \backslash\{i\})$, for all $i$, in all TSPNE. The strong subadditivity property (see Laussel and Le Breton (2001, p. 104) for a formal definition) is stronger than the strict additivity property used in this paper. The two properties coincide for $\# N=2$ only.

${ }^{13}$ The conjecture that an agent in charge of $\mathrm{R} \& \mathrm{D}$ activities may have no superior information about project returns before acting dates back from Holmstrom (1989), who sees it as a "reasonable assumption if we are at the initial stages of a research undertaking" (p. 310). Interestingly, this falls in line with the specifications of a theoretical paper on common agency by Laussel and Le Breton (1998), who introduce a random parameter in the agent's cost function which is not realized at the contracting stage. In this setting, the laboratory's cost would become $\mu s(\mathbf{x})$, where $\mu$ is a positive random variable. The laboratory would not know the realization of $\mu$ before accepting or refusing the firms' contracts (that is, strategies $t_{i}(\mathbf{x})$ in our notation, $i=1,2$ ), but would learn it before producing $\mathrm{R} \& \mathrm{D}$ services (that is, $\mathbf{x}$ ).

\footnotetext{
${ }^{14}$ Lemma 1- $(i i)$ implies that $\delta_{\check{x}_{j}=\hat{x}_{j}=0}=\delta_{x^{\mathrm{d}}=x^{\mathrm{n}}}<\delta_{\mathcal{L}=0}$
} 


\section{References}

Aghion, Philippe, and Jean Tirole (1994) 'On the management of innovation.' Quarterly Journal of Economics 109(4), 1185-1290

Ambec, Stefan, and Michel Poitevin (2001) 'Organizational design of R\&D activities.' Technical Report 38, CIRANO, Montreal, Quebec, Canada

Amir, Rabah (2000) 'Modelling imperfectly appropriable R\&D via spillovers.' International Journal of Industrial Organization 18(7), 1013-1032

Amir, Rabah, Igor Evstigneev, and John Wooders (2003) 'Noncooperative versus cooperative R\&D with endogenous spillover rates.' Games and Economc Behavior 42(2), 183-207

Argyres, Nicholas S., and Julia Porter Liebeskind (2002) 'Governance inseparability and the evolution of US biotechnology industry.' Journal of Economic Behavior and Organization 47(2), 197-219

Atallah, Gamal (2002) 'Vertical R\&D spillovers, cooperation, market structure, and innovation.' Economics of Innovation and New Technology 11(3), 179-209

Banerjee, Samiran, and Ping Lin (2001) 'Vertical research joint ventures.' International Journal of Industrial Organization 19(1), 285-302

- (2003) 'Downstream R\&D, raising rivals' costs, and input price contracts.' International Journal of Industrial Organization 21(1), 79-96

Bernheim, B. Douglas, and Michael D. Whinston (1986) 'Menu auctions, resource allocation, and economic influence.' Quarterly Journal of Economics 101(1), 1-32

Billete de Villemeur, Etienne, and Bruno Versaevel (2003) 'From private to public common agency.' Journal of Economic Theory 111(2), 305-309

Brocas, Isabelle (2003) 'Vertical integration and incentives to innovate.' International Journal of Industrial Organization 21(4), 457-488

Crémer, Jacques, and Michael H. Riordan (1987) 'On governing multilateral transactions with bilateral contracts.' RAND Journal of Economics 18(3), 436-451 
d'Aspremont, Claude, and Alexis Jacquemin (1988) 'Cooperative and noncooperative R\&D in duopoly with spillovers.' American Economic Review 78(5), 1133-1137

Dobler, Donald W., and David N. Burt (1996) Purchasing and Supply Management: Text and Cases, sixth ed. (New York, New York: McGraw-Hill)

Hinloopen, Jeroen (2000) 'Strategic R\&D cooperatives.' Research in Economics 54(2), 153-185

Holmstrom, Bengt (1989) 'Agency costs and innovation.' Journal of Economic Behavior and Organization 12(3), 305-327

Howells, Jeremy, Andrew James, and Khaleel Malik (2003) 'The sourcing of technological knowledge: distributed innovation processes and dynamic change.' RESD Management 33(4), 395-409

Ishii, Akira (2004) 'Cooperative R\&D between vertically related firms with spillovers.' International Journal of Industrial Organization. Forthcoming

Kamien, Morton, Eitan Muller, and Israel Zang (1992a) 'Research joint ventures and R\&D cartels.' American Economic Review 82(5), 1293-1306

Kamien, Morton I., and Israel Zang (2000) 'Meet me halfway: research joint ventures and absorptive capacity.' International Journal of Industrial Organization 18(7), 995-1012

Kamien, Morton I., Shumel S. Oren, and Yair Tauman (1992b) 'Optimal licensing of cost-reducing innovation.' Journal of Mathematical Economics 21(5), 483-508

Kamien, Morton I., Yair Tauman, and Israel Zang (1988) 'Optimal license fees for a new product.' Mathematical Social Sciences 16(1), 77-106

Katz, Michael L., and Carl Shapiro (1986) 'How to license intangible property.' Quarterly Journal of Economics 101(3), 520-567

Laffont, Jean-Jacques, and David Martimort (1997) 'The firm as a multicontract organization.' Journal of Economics and Management Strategy 6(2), 201-234.

Laussel, Didier, and Michel Le Breton (1998) 'Efficient private production of public goods under common agency.' Games and Economic Behavior 25(2), 194-218 
- (2001) 'Conflict and cooperation: The structure of equilibrium payoffs in common agency.' Journal of Economic Theory 100(1), 93-128

Lerner, Josh, and Robert P. Merges (1998) 'The control of technology alliances: An empirical analysis of the biotechnology industry.' The Journal of Industrial Economics 46(2), 125-156

Martimort, David, and Lars Stole (2003a) 'Contractual externalities in common agency games.' Advances in Theoretical Economics 3(1), Article 4.

http://www.bepress.com/bejte/advances/vol3/iss1/art4

— (2003b) 'Market participation under delegated and intrinsic common agency games.' Université de Toulouse and University of Chicago, Mimeo

Martin, Stephen (2001) 'Strategic research partnerships: Evidence and analysis.' In Strategic Research Partnerships: Proceedings from an NSF Workshop, ed. Nicholas S. Vonortas John E. Jankowski, Albert N. Link National Science Foundation, Division of Science Resources Studies National Science Foundation 4201 Wilson Blvd., Suite 965, Arlington, VA 22230. http://www.nsf.gov/sbe/srs/nsf01336/p1s1.htm

Milgrom, Paul, and John Roberts (1990) 'The economics of modern manufacturing: technology, strategy, and organization.' American Economic Review 80(3), 511-528

Motta, Massimo (1992) 'Cooperative R\&D and vertical product differentiation.' International Journal of Industrial Organization 10(4), 643-661

National Science Foundation (2003) 'Survey of industrial research and development: 2000.' NSF. 198 pages

Poyago-Theotoky, Joanna (1999) 'A note on endogenous spillovers in a non-tournament R\&D duopoly.' Review of Industrial Organization 13(3), 249-276

Rosenkranz, Stephanie (1995) 'Innovation and cooperation under vertical product differentiation.' International Journal of Industrial Organization 13(1), 1-22 
Suzumura, Kotaro (1992) 'Cooperative and noncooperative R\&D in an oligopoly with spillovers.' American Economic Review 82(5), 1307-1320

Symeonidis (2003) 'Comparing cournot and bertrand equilibria in a differentiated duopoly with product R\&D.' International Journal of Industrial Organization 12(1), 39-55

Vonortas, Nicholas S. (1994) 'Inter-firm cooperation with imperfectly appropriable research.' International Journal of Industrial Organization 12(3), 413-435 


\section{Liste des cahiers de recherche publiés par les professeurs des H.E.C. 2003-2004}

\section{Institut d'économie appliquée}

IEA-03-01 GAGNÉ; ROBERT; LÉGER, PIERRE THOMAS. « Determinants of Physicians’ Decisions to Specialize »,29 pages.

IEA-03-02 DOSTIE, BENOIT. «Controlling for Demand Side Factors and Job Matching: Maximum Likelihood Estimates of the Returns to Seniority Using Matched Employer-Employee Data »,24 pages.

IEA-03-03 LAPOINTE, ALAIN. « La performance de Montréal et l'économie du savoir: un changement de politique s'impose », 35 pages.

IEA-03-04 NORMANDin, MICHEL; PhAneuf, LOUIS. « Monetary Policy Shocks: Testing Identification Conditions Under Time-Varying Conditional Volatility », 43 pages.

IEA-03-05 BOILEAU, MARTIN; NORMANDin, MiCHEL. « Dynamics of the Current Account and Interest Differentials », 38 pages.

IEA-03-06: NORMANDIN, MICHEL; ST-AMOUR, PASCAL. « Recursive Measures of Total Wealth and Portfolio Return », 10 pages.

IEA-03-07: DOSTIE, BENOIT; LÉGER, PIERRE THOMAS. « The Living Arrangement Dynamics of Sick, Elderly Individuals », 29 pages.

IEA-03-08: NORMANDIN, MICHEL. « Canadian and U.S. Financial Markets: Testing the International Integration Hypothesis under Time-Varying Conditional Volatility », 35 pages. 
IEA-04-01: LEACH, ANDREW. «Integrated Assessment of Climate Change Using an OLG Model », 34 pages.

IEA-04-02: LEACH, ANDREW. "SubGame, set and match. Identifying Incentive Response in a Tournament », 39 pages.

IEA-04-03: LEACH, ANDREW. « The Climate Change Learning Curve », 27 pages.

IEA-04-04: DOSTIE, BENOIT; VENCATACHELLUM, DÉSIRÉ. « Compulsory and Voluntary Remittances: Evidence from Child Domestic Workers in Tunisia », 46 pages.

IEA-04-05: RENGIFO, E.W.; ROMBOUTS, J.V.K. « Dynamic Optimal Portfolio in a VaR Framework », 33 pages.

IEA-04-06: DOSTIE, BENOIT; TRÉPANIER, MATHIEU. « Return to Computer Use and Organizational Practices of the Firm », 41 pages.

IEA-04-07: ALLARD, MARIE; LÉGER, PIERRE THOMAS; ROCHAIX, LISE. « Provider Competition in a Dynamic Setting » 32 pages

IEA-04-08: MAURICE N. MARCHON. «Perspectives économiques canadiennes dans un contexte international » 27 pages.

IEA-04-09: NORMANDIN, MICHEL. " The Current Account and the Interest Differential in Canada », 27 pages.

IEA-04-10 AZAM, JEAN-PAUL; GAUTHIER, BERNARD; GOYETTE, JONATHAN. « The Effect of Fiscal Policy and Corruption Control Mechanisms on Firm Growth and Social Welfare: Theory and Evidence », 45 pages.

IEA-04-11 RUTH DUPRÉ. «The Prohibition of Alcohol Revisited : the US Case in International Perspective », 28 pages.

IEA-04-12 BÉLAIR, MARJOLAINE; GAUTHIER, BERNARD. «Les effets de l'immigration sur le commerce bilatéral : le cas de l’Australie et des pays de l’Asie du Sud-Est », 50 pages.

IEA-04-13 LAROCQue, DENIS; NORMANDin, MICHEL. «Econometric Inference, Cyclical Fluctuations, and Superior Information », 40 pages.

IEA-04-14 ROMBouts, JEROEN V.K.; VERBEEK MARNO. « Evaluating Portfolio Value-at-Risk Using Semi-parametric Garch Models », 30 pages. 